\title{
Bimanual Coordination and Corpus Callosum Microstructure in Young Adults with Traumatic Brain Injury: A Diffusion Tensor Imaging Study
}

\author{
Karen Caeyenberghs, Alexander Leemans, 2 James Coxon,, Inge Leunissen,, David Drijkoningen, \\ Monique Geurts, Jolien Gooijers, Karla Michiels, ${ }^{3}$ Stefan Sunaert, ${ }^{4}$ and Stephan P. Swinnen ${ }^{1}$
}

\begin{abstract}
Bimanual actions are ubiquitous in daily life. Many coordinated movements of the upper extremities rely on precise timing, which requires efficient interhemispheric communication via the corpus callosum (CC). As the $\mathrm{CC}$ in particular is known to be vulnerable to traumatic brain injury (TBI), furthering our understanding of its structure-function association is highly valuable for TBI diagnostics and prognosis. In this study, 21 young adults with TBI and 17 controls performed object manipulation tasks (insertion of pegs with both hands and bilateral daily life activities) and cognitive control tasks (i.e., switching maneuvers during spatially and temporally coupled bimanual circular motions). The structural organization of 7 specific subregions of the CC (prefrontal, premotor/supplementary motor, primary motor, primary sensory, parietal, temporal, and occipital) was subsequently investigated in these subjects with diffusion tensor imaging (DTI). Findings revealed that bimanual coordination was impaired in TBI patients as shown by elevated movement time values during daily life activities, a decreased number of peg insertions, and slower response times during the switching task. Furthermore, the DTI analysis demonstrated a significantly decreased fractional anisotropy and increased radial diffusivity in prefrontal, primary sensory, and parietal regions in TBI patients versus controls. Finally, multiple regression analyses showed evidence of the high specificity of callosal subregions accounting for the variance associated with performance of the different bimanual coordination tasks. Whereas disruption in commissural pathways between occipital areas played a role in performance on the clinical tests of bimanual coordination, deficits in the switching task were related to disrupted interhemispheric communication in prefrontal, sensory, and parietal regions. This study provides evidence that structural alterations of several subregional callosal fibers in adults with TBI are associated with differential behavioral manifestations of bimanual motor functioning.
\end{abstract}

Key words: bimanual coordination; corpus callosum; diffusion tensor MRI; traumatic brain injury

\section{Introduction}

$\mathbf{M}$ ANY TRAUMATIC BRAIN INJURY (TBI) patients regain their abilities for activities of daily living, but are nevertheless faced with severe deficits, such as reduced movement speed and accuracy despite rehabilitation (Chaplin et al., 1993; Kuhtz-Buschbeck et al., 2003a, 2003b; Rossi and Sullivan, 1996). Clumsy and slow performance may be a considerable handicap to these patients, especially if a high degree of collaboration between the hands is required, such as opening a bottle, driving a car, playing musical instruments, or typing. Research on the structural brain alterations that determine bimanual coordination deficits may facilitate treatments and may help elucidate the pathophysiology of motor recovery after TBI.

Functional neuroimaging studies of bimanual coordination have identified a widespread brain activation pattern including the primary sensorimotor cortex (M1/S1), supplementary motor area (SMA), cingulate motor cortex, lateral premotor cortex, parietal cortex, and subcortical structures,

\footnotetext{
${ }^{1}$ Motor Control Laboratory, Research Center for Movement Control and Neuroplasticity, K.U. Leuven, Belgium.

${ }^{2}$ Image Sciences Institute, University Medical Center Utrecht, Utrecht, The Netherlands.

${ }^{3}$ Department of Physical Medicine and Rehabilitation, University Hospital Leuven Campus Pellenberg, Belgium.

${ }^{4}$ Department of Radiology, University Hospital, K.U. Leuven, Belgium.
} 
such as the basal ganglia and cerebellum (Debaere et al., 2004; Deiber et al., 2001; Immisch et al., 2001; Jancke et al., 2000a, 2000b; Kermadi et al., 2000; Sadato et al., 1997a, 1997b; Stephan et al., 1999a, 1999b; Wenderoth et al., 2004, 2005a, 2005b; Wu et al., 2010; for a review, see Swinnen, 2002, and Swinnen and Wenderoth, 2004). Such a distributed network of corticosubcortical regions requires a dedicated structure of white matter (WM) tracts to communicate essential signals between the hemispheres. One of these major WM tracts is the corpus callosum (CC), connecting both homotopic and heterotopic cortical regions. The CC is composed of densely packed, myelinated axons and is commonly partitioned into ordered subareas based on anatomical and functional connectivity between cortical regions. Studies on patients who underwent partial or complete callosotomy have demonstrated bimanual coordination deficits (Eliassen et al., 2000; Larson et al., 2002; Serrien et al., 2001; Sternad et al., 2007).

There are only a few diffusion tensor imaging (DTI) studies that have identified WM properties of the CC that vary with bimanual coordination performance. For example, in a study of 10 healthy adults, Johansen-Berg and colleagues (2007) found relationships between bimanual coordination and fractional anisotropy (FA) of the CC midbody. Bonzano and associates (2008) reported correlations between FA of the anterior CC and bimanual finger opposition movements in patients with multiple sclerosis. Muetzel and colleagues (2008) also reported regression analyses in which the speed of alternating finger tapping in adolescents was predicted by FA of the splenium, gender, and age. These findings are informative for our understanding of the contribution of callosal microstructure to bimanual coordination. However, none of these studies included multiple task conditions, thereby varying the degree and nature of interhemispheric communication required.

In addition to these recent studies, DTI studies in TBI patients have shown abnormal callosal anisotropy values (Ewing-Cobbs et al., 2006, 2008; Kraus et al., 2007; Rutgers et al., 2008; Wilde et al., 2006; Wozniak et al., 2007). For example, Wilde and colleagues (2006) found reduced FA values in TBI patients for the genu, body, and splenium of the CC. The group also reported correlations between mean FA in the total $\mathrm{CC}$ and functional outcome as measured by the dichotomized Glasgow Outcome Scale. Although these studies revealed a great deal about the overall microstructural organization of the CC, they lack direct information about specific subregions of the CC and how their structural properties relate to bimanual coordination deficits.

The present study was designed to overcome the limitations associated with the aforementioned studies by expanding the battery of bimanual tasks to assess a broader functional repertoire in TBI patients and controls by embracing clinical and laboratory tasks. The first aim was to determine whether TBI patients showed an impaired bimanual coordination performance as compared to normal subjects. More specifically, we investigated both bimanual object manipulation tasks (i.e., insertion of pegs and daily life activities), and cognitive control tasks (requiring switching between different coordination modes).

Then we explored the microstructural organization of seven CC subregions of interest with DTI. The majority of the abovementioned DTI studies examined only three subregions of the CC (genu, body, and splenium), or relied on segmen- tation of the CC into subregions based on geometric measures of length and distance, which may not necessarily reflect functionally distinct regions (such as in Witelson, 1989). Moreover, earlier subdivisions were often suboptimal because these were based on experimental work conducted with non-human primates. For example, recent work has shown that callosal fibers connecting the primary motor cortices are clearly more posterior in humans (Hofer and Frahm, 2006; Wahl et al., 2007). In our study, we used a tractography-based parcellation method that is more likely to relate to functionality (Behrens et al., 2003; Hofer and Frahm, 2006; Huang et al., 2006). We subdivided the CC into seven subregions based on its connections to the (1) prefrontal regions, (2) premotor and supplementary motor areas, (3) primary motor cortex, (4) primary sensory cortex, and (5) parietal, (6) temporal, and (7) occipital cortex.

Our ultimate goal was to investigate whether the different expressions of bimanual motor behavior were associated with localized and anatomically specific damage according to the seven CC subregions in TBI patients. Higher-level multimetric analyses were employed to specifically characterize and discriminate behavioral deficits in TBI patients, and to predict pathology and identify motor outcome measures for follow-up.

\section{Methods}

\section{Participants}

Thirty-eight adults participated in the study, including 21 patients with moderate to severe TBI (mean age 25 years 6 months; SD 5 years 4 months; 15 males and 6 females), who had sustained closed head trauma due to traffic accident or sport injury that averaged 4 years 3 months prior to the study (SD 2 years 5 months), and 17 control subjects (mean age 25 years; SD 1 year 8 months; 8 males and 9 females). The TBI patients were classified as moderate-to-severe based on several factors: the post-resuscitation Glasgow Coma Scale (GCS) score when available (mean GCS score 8, SD 3.7; data were only available for 4 patients), the duration of loss of consciousness ( $30 \mathrm{~min}$ or more), the length of post-traumatic amnesia ( $>1$ day), the anatomical features of the injury based on inspection by an expert neuroradiologist, and the injury mechanism (traffic accidents and falls), or combinations thereof. Exclusion criteria included: neurosurgery, except for invasive intracranial pressure monitoring; a history of psychiatric or neurological illness prior to the head injury; a history of previous TBI; anti-epileptic medication; current or previous drug or alcohol abuse; or contraindication to magnetic resonance imaging (MRI).

The structural MRI scans were inspected and classified by an experienced neuroradiologist (S.S.) using the scheme of Adams and associates (1989), which allows the identification of three grades of diffuse axonal injury (Table 1 ). In grade 1 there is histological evidence of axonal injury in the white matter of the cerebral hemispheres, the corpus callosum, the brainstem, and less commonly, the cerebellum; in grade 2 there is also a focal lesion in the corpus callosum; and in grade 3 there is also a focal lesion in the dorsolateral quadrant or quadrants of the rostral brainstem. The median severity score of the TBI patients was 2 (range 0-2.5). Demographic and neurologic variables are provided in Table 1 . The 17 control subjects had normal medical histories and MRI scans were 
Table 1. Summary of Demographic and Injury Characteristics for the TBI Group

\begin{tabular}{|c|c|c|c|c|}
\hline $\begin{array}{l}\text { TBI patient no. } \\
\text { Age/gender/handedness }\end{array}$ & $\begin{array}{l}\text { Age at } \\
\text { injury }\end{array}$ & $\begin{array}{l}\text { Acute scan within } 24 h \\
\text { after injury Lesion } \\
\text { location/pathology }\end{array}$ & $\begin{array}{l}\text { MRI scan at examination } \\
\text { Lesion location/pathology }\end{array}$ & $\begin{array}{l}\text { TBI severity } \\
\text { score }\end{array}$ \\
\hline TBI 1 27.6/F/RH & 25,2 & $\begin{array}{l}\text { TL contusion, (R) PL } \\
\text { hemorrhage, (L) FL } \\
\text { intraparenchymal } \\
\text { hemorrhagic contusion, } \\
\text { subdural hematoma }\end{array}$ & $\begin{array}{l}\text { Drain tract }(\mathrm{R}),(\mathrm{L}) \mathrm{FL} \text { and } \mathrm{TL} \\
\text { contusion }\end{array}$ & 2 \\
\hline TBI 2 22.9/F/RH & 21,3 & $\begin{array}{l}\text { (R) FL hemorrhage, (L) FL/TL } \\
\text { and (L) PL and (R) orbito- } \\
\text { frontal cortex contusion }\end{array}$ & $\begin{array}{l}\text { Drain tract }(\mathrm{R}) \text {, hemosiderin } \\
\text { deposits (R) PL and (R) } \\
\text { orbito-frontal cortex }\end{array}$ & 1 \\
\hline TBI 3 22.5/M/RH & 17,6 & $\begin{array}{l}\text { (L) FL shearing injuries, } \\
\text { splenium and body corpus } \\
\text { callosum contusion }\end{array}$ & (R) FL contusion & 1 \\
\hline TBI 4 28.1/M/RH & 18,6 & $\begin{array}{l}\text { FL contusion, (L) FL subdural } \\
\text { hematoma, (L) TL and (R) } \\
\text { PL hemorrhage }\end{array}$ & Drain tract $(\mathrm{L})$, FL contusion & 1.5 \\
\hline TBI 5 17.9/F/RH & 12,9 & $\begin{array}{l}\text { Contusion (location not } \\
\text { specified in available } \\
\text { records) }\end{array}$ & & 0 \\
\hline TBI 6 30.8/M/RH & 24,8 & (L) FL/PL contusion & $\begin{array}{l}\text { FL shearing injuries } \\
\text { periventricular white } \\
\text { matter }\end{array}$ & 1 \\
\hline TBI 7 34.6/M/RH & 28,9 & $\begin{array}{l}\text { (R ) amygdala and basal } \\
\text { ganglia and (R ) PL } \\
\text { hemorrhage, (L) FL } \\
\text { inflammatory changes }\end{array}$ & (L) TL contusion & 1 \\
\hline TBI 8 16.8/M/RH & 9,1 & $\begin{array}{l}\text { (L ) TL and (L) FL punctiform } \\
\text { and (R ) mesencephalon } \\
\text { contusion, (L) FL and (L) } \\
\text { thalamus hemorrhagic } \\
\text { injuries }\end{array}$ & $\begin{array}{l}\text { Orbito-fronal cortex } \\
\text { contusion, enlarged } \\
\text { ventricles }\end{array}$ & 1 \\
\hline TBI 9 33.8/M/RH & 27,9 & & $\begin{array}{l}\text { Drain tract (R), thalamus } \\
\text { injury, corpus callosum } \\
\text { shearing injuries, (R) FL and } \\
\text { (L) inferior FL and (R) OL } \\
\text { contusion }\end{array}$ & 2.5 \\
\hline TBI 10 26.9/F/RH & 23,9 & FL injuries & $\begin{array}{l}\text { Drain tract }(\mathrm{L}), \mathrm{PL} \text { and OL/PL } \\
\text { and FL and (R) TL shearing } \\
\text { injuries, slightly enlarged } \\
\text { ventricles }\end{array}$ & 1 \\
\hline TBI 11 28.3/F/RH & 21,9 & $\begin{array}{l}\text { FL and (L) TL perfusion } \\
\text { deficits }\end{array}$ & $\begin{array}{l}\text { Drain tract }(\mathrm{R}) \text {, wide extended } \\
\text { FL contusion, cerebellar } \\
\text { atrophy }\end{array}$ & 2 \\
\hline TBI 12 22.3/M/RH & 19,1 & $\begin{array}{l}\text { Contusion and DAI (location } \\
\text { not specified in available } \\
\text { records) }\end{array}$ & $\begin{array}{l}\text { (L) thalamus and (L) TL and } \\
\text { (L) orbito-frontal cortex and } \\
\text { (L) FL and (R) FL and } \\
\text { central sulcus shearing } \\
\text { injuries }\end{array}$ & 2 \\
\hline TBI 13 31.7/M/RH & 29,6 & $\begin{array}{l}\text { (L) FL/TL hemorrhage and } \\
\text { DAI, FL and TL/OL } \\
\text { shearing injuries }\end{array}$ & $\begin{array}{l}\text { TL and (R) orbito-frontal } \\
\text { cortex and (R) inferior FL } \\
\text { contusion, corpus callosum } \\
\text { degeneration, asymmetric } \\
\text { ventricles, (L) PL shearing } \\
\text { injury }\end{array}$ & 2 \\
\hline TBI 14 16.7/M/RH & 14,5 & $\begin{array}{l}\text { Enlarged (R) lateral ventricle, } \\
\text { (R) hematoma occipital } \\
\text { horn lateral ventricle, } \\
\text { hyperdensity (L) thalamus } \\
\text { and PL/TL, (LH) shearing } \\
\text { injuries }\end{array}$ & $\begin{array}{l}\text { Drain tract (R), (L) corpus } \\
\text { callosum and thalamus and } \\
\text { (R) PL and (L) FL and (R) } \\
\text { TL shearing injuries, } \\
\text { occipital horn lateral } \\
\text { ventricle asymmetrically } \\
\text { enlarged }\end{array}$ & 2 \\
\hline
\end{tabular}


TABle 1. (CONTINUED)

\begin{tabular}{|c|c|c|c|c|}
\hline $\begin{array}{l}\text { TBI patient no. } \\
\text { Age/gender/handedness }\end{array}$ & $\begin{array}{l}\text { Age at } \\
\text { injury }\end{array}$ & $\begin{array}{l}\text { Acute scan within } 24 h \\
\text { after injury Lesion } \\
\text { location/pathology }\end{array}$ & $\begin{array}{l}\text { MRI scan at examination } \\
\text { Lesion location/pathology }\end{array}$ & $\begin{array}{c}\text { TBI severity } \\
\text { score }\end{array}$ \\
\hline TBI 15 28.1/M/RH & 18,4 & $\begin{array}{l}\text { Hemosiderin deposits corpus } \\
\text { callosum, DAI, ischemic } \\
\text { injury (L) occipital horn of } \\
\text { lateral ventricle }\end{array}$ & $\begin{array}{l}\text { Drain tract }(\mathrm{R}),(\mathrm{R}) \\
\text { periventricular white } \\
\text { matter FL and thalamus } \\
\text { injuries, corpus callosum } \\
\text { degeneration }\end{array}$ & 2 \\
\hline TBI 16 27.9/M/RH & 24,9 & $\begin{array}{l}\text { (L) thalamus and }(\mathrm{L}) \\
\text { periventricular and corpus } \\
\text { callosum and brainstem } \\
\text { and TL shearing injuries }\end{array}$ & $\begin{array}{l}\text { Drain tract, }(\mathrm{L}) \text { thalamus and } \\
\text { corpus callosum and (L) TL } \\
\text { shearing injuries }\end{array}$ & 2 \\
\hline TBI 17 30.9/M/RH & 28,3 & $\begin{array}{l}\text { Lesion and location not } \\
\text { specified in available } \\
\text { records }\end{array}$ & $\begin{array}{l}\text { Drain tract }(\mathrm{R}),(\mathrm{L}) \text { inferior TL } \\
\text { contusion, }(\mathrm{L}) \text { anterior } \\
\text { cingulate and (R) FL and } \\
\text { central sulcus shearing } \\
\text { injuries }\end{array}$ & 2 \\
\hline TBI 18 24.1/M/RH & 21,8 & $\begin{array}{l}\text { (L) FL hematoma, FL } \\
\text { intraparenchymal } \\
\text { hemorrhage, } \\
\text { subarachnoidal bleeding }\end{array}$ & $\begin{array}{l}\text { Drain tract }(\mathrm{R}) \text {, orbito-frontal } \\
\text { cortex and }(\mathrm{L}) \text { cerebellum } \\
\text { contusion }\end{array}$ & 2 \\
\hline TBI 19 19.2/M/RH & 16,5 & $\begin{array}{l}\text { Lesion and location not } \\
\text { specified in available } \\
\text { records }\end{array}$ & $\begin{array}{l}\text { Drain tract (R), corpus } \\
\text { callosum degeneration, } \\
\text { central sulcus and SMA and } \\
\text { corpus callosum shearing } \\
\text { injuries }\end{array}$ & 2 \\
\hline TBI 20 26.3/M/RH & 23,6 & $\begin{array}{l}\text { Contusion location not } \\
\text { specified in available } \\
\text { records }\end{array}$ & $\begin{array}{l}\text { Corpus callosum and body } \\
\text { nucleus caudatus shearing } \\
\text { injury }\end{array}$ & 2 \\
\hline TBI 21 20.6/F/RH & 18,1 & $\begin{array}{l}\text { Diffuse axonal injuries, (L) } \\
\text { FL/TL/PL subdural } \\
\text { hematoma, FL contusion, } \\
\text { injuries corpus callosum }\end{array}$ & $\begin{array}{l}\text { FL and (R) PL contusion, } \\
\text { orbito-frontal cortex } \\
\text { shearing injuries, enlarged } \\
\text { ventricles }\end{array}$ & 2 \\
\hline
\end{tabular}

RH, right hemisphere; LH, left hemisphere; FL, frontal lobe; TL, temporal lobe; PL, parietal lobe; OL, occipital lobe; R, right; L, left; TBI, traumatic brain injury; MRI, magnetic resonance imaging; $\mathrm{RH}$, right-handed; $\mathrm{LH}$, left-handed; $\mathrm{M}$, male; F, female.

rated as being normal by a radiologist. All subjects were righthanded (laterality quotient: TBI: mean 81, range 22-100; control: mean 92; range 60-100) as verified by the Edinburgh Handedness Inventory (Oldfield, 1971). The study was approved by the local ethics committee for biomedical research. Informed consent was obtained from each patient or from the patient's first-degree relatives.

\section{Behavioral testing}

Assessment of bimanual coordination was performed using both clinical and instrumented measures. First, bilateral items of the TEMPA and the Purdue Pegboard Test were administered individually to each study participant. Second, we used a task requiring participants to continuously trace bimanual circles. Both tasks reveal different aspects of bimanual coordination underscoring their complementarity.

TEMPA (Test d'Evaluation de la performance des Membres Superieurs des Personnes Agees). The TEMPA was developed by Desroisiers in 1993 and is composed of nine standardized tasks which simulate activities of daily life. The clinical utility of the TEMPA was evaluated to be higher than other tests such as the Jebsen Handfunction Test, Action Research Arm Test, the Nine Hole Peg Test, and Rivermead Motor Assessment, because the tasks refer to activities of daily life with the inclusion of bilateral tasks and the use of a variety of real objects. Its reliability and validity have been shown in previous studies on aging (Desrosiers et al., 1995a), as well as in patients with multiple sclerosis (Feys et al., 2002), stroke (Higgins et al., 2006), and TBI (Moseley and Yap, 2003; Platz et al., 2001). Four items are unilateral (pick up and move a jar, pick up a pitcher and pour water into a glass, handle coins, and pick up and move small objects), and five are bilateral (open a jar and take a spoonful of coffee, unlock a lock and open a pill container, write on an envelope and stick on a stamp, shuffle and deal playing cards, and put a scarf around one's neck). Standardized equipment was used for each task. The outcome parameter used in this study was movement time (seconds) across the five bilateral tasks. A high score indicated poor performance.

\section{Purdue Pegboard Test}

The Purdue Pegboard Test consists of manipulating small pins on a board as quickly as possible in a 30-sec time period (Desrosiers et al., 1995b; Tiffinn and Asher, 1948). The participants were allowed to practice with 3 or 4 pins before starting. The test was performed three times with both hands. The dependent variable was the mean number of pegs placed during the 3 trials. Contrary to the previous test, a high score indicates good performance. 


\section{Switching task}

Besides clinical testing, participants were required to switch between coordination modes while making spatially and temporally coupled circular motions with joysticks. This task assesses cognitive control processes that are particularly affected in TBI patients (Cicerone et al., 2005; Powell and Voeller, 2004; Rees et al., 2007). We used a protocol that has been used in an fMRI study in young and elderly healthy subjects (Coxon et al., 2010). For each hand, the direction of circling could be either clockwise (CW) or counter-clockwise (CCW). An auditory metronome was used for pacing such that participants completed one circle per tone. Four possible bimanual movement patterns were introduced: inward circles (left hand CW, right hand CCW), outward circles (left hand $\mathrm{CCW}$, right hand $\mathrm{CW}$ ), clockwise circles (both hands $\mathrm{CW}$ ), and counter-clockwise circles (both hands CCW). Inward and outward circling are symmetric bimanual movements, and clockwise/counterclockwise circling are asymmetric. A constant visual display was shown comprising two white circles, each with a curved white bar immediately above, and a central fixation cross on a black background. Instruction cues were conveyed by arrows, visible for $800 \mathrm{msec}$ (Fig. 1). Green arrows were used as imperative cues. The initial pattern to adopt was indicated by two green arrows. A single green arrow pointing opposite to the actual movement direction indicated that the right hand must change direction (SW, switch). This resulted in a change of movement pattern from asymmetric to symmetric circling (SW-SYMM, easy switch), or from symmetric to asymmetric circling (SW-ASYMM, hard switch). A single green arrow pointing in the same direction as the actual movement indicated that no change was necessary for the right hand (continue). In both cases, the left hand was to maintain moving in the already established direction. White arrows indicated the correct movement pattern $4 \mathrm{sec}$ after the imperative cue. For participants, this served as confirmation that they were performing the correct pattern, or it provided an opportunity to correct their error.
Prior to the experiment, participants received a description of the task and the maximum stable movement frequency was determined. Participants made circular motions about the wrist and metacarpophalangeal joints with their left and right index fingers by means of two custom joysticks, with their forearms supported at approximately $45^{\circ}$ from the horizontal. They were cued to move in an asymmetric pattern (both hands $\mathrm{CW}$ or $\mathrm{CCW}$ ), and metronome frequency was increased every $8 \mathrm{sec}$ from $1-3 \mathrm{~Hz}$ in $0.25-\mathrm{Hz}$ increments. The participant's maximum stable movement frequency was determined by online inspection of the relative tangential angle (Carson et al., 1997). When either a spontaneous transition occurred or the temporal relationship to the metronome could no longer be maintained, the maximum stable frequency was recorded. Participants were paced at $50 \%$ of their maximum. This procedure served to establish common relative speeds, equating the difficulty of bimanual circling between groups. After establishing the maximum movement frequency, participants performed a training session to ensure that each subject could perform the task proficiently.

During the experiment, subjects performed five trial blocks, each $352 \mathrm{sec}$ in duration. A block comprised alternating movement $(68 \mathrm{sec})$ and rest $(20 \mathrm{sec})$ epochs to avoid fatigue. There were 14 switch trials, 14 continue trials, 4 reverse trials, and 32 confirmation trials per block. Reverse trials were signaled by two green arrows, cueing a switch of both hands. They were included to change left hand direction within a movement epoch, but were of no interest for the analysis. One of the four possible movement patterns was used as an initial pattern for each movement epoch and the order was counterbalanced across runs. In total, there were 70 switch trials of the right hand (35 SW-SYMM and 35 SW-ASYMM) and 70 continue trials. It is important to note that only the switch trials were accompanied by a cognitive load.

Joystick movements were registered by two compatible optical encoders (spatial resolution $0.18^{\circ}$ ) mounted along orthogonal axes. Custom LabVIEW software recorded the twodimensional kinematics of each joystick (sample rate $100 \mathrm{~Hz}$ )
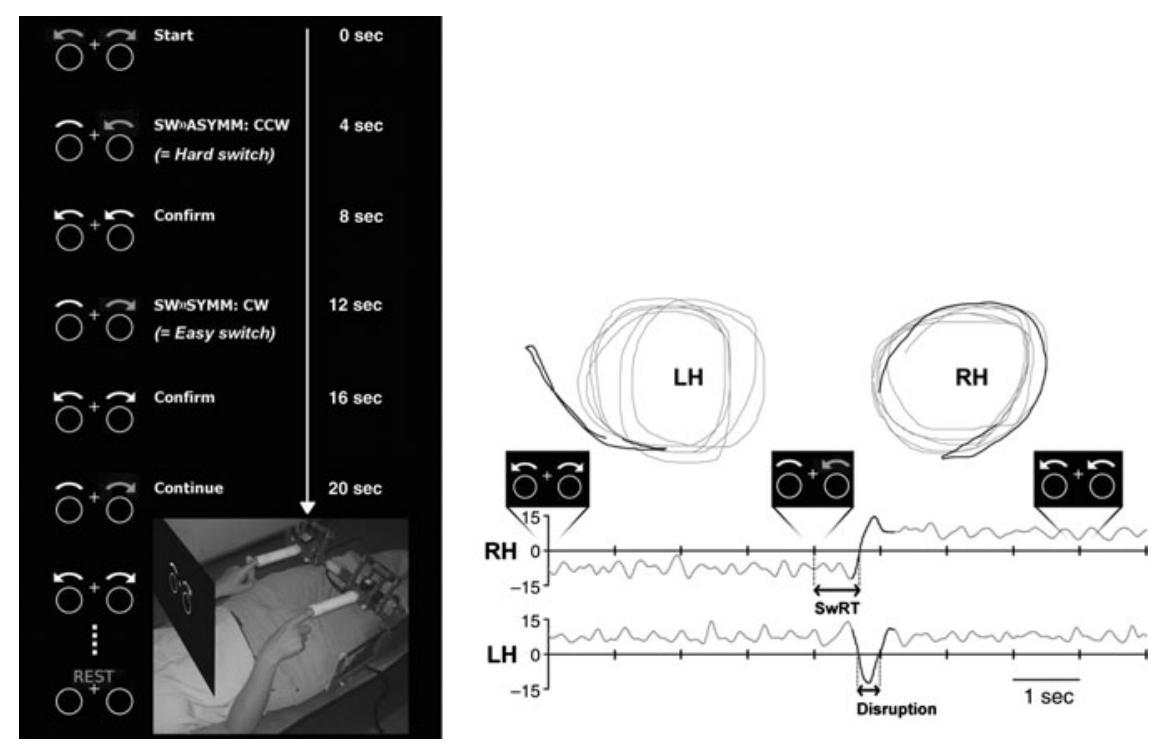

FIG. 1. Set-up of motor switching task (SwRT, switch response time; CW, clockwise; CCW, counter-clockwise; SW-SYMM, switch to symmetric circling; SW-ASYMM, switch from symmetric to asymmetric circling; RH, right hand; LH, left hand). 
and generated the visual display. Cues were projected onto a screen and viewed via a $45^{\circ}$ mirror. Participants could see the visual display but the joysticks were obscured.

MATLAB 7.7 (Mathworks, Sherborn, MA) was used to analyze the kinematic data of the switching task. For each hand a continuous estimate of angular velocity was determined by $\omega=\mathrm{d} \theta / \mathrm{dt}$ with $\theta=\arctan (\mathrm{x} / \mathrm{y})$, where $\mathrm{x}$ and $\mathrm{y}$ describe the mean corrected values for vertical and horizontal joystick displacements, respectively. A second-order Butterworth low-pass filter (cutoff $5 \mathrm{~Hz}$ ) was applied to $\omega$. For trials when the right hand changed direction, switch response time (SwRT) was determined as the interval between stimulus onset and the first zero crossing of $\omega$, indicating that cycling direction had reversed. This measure is an indication of the speed with which an ongoing coordination pattern is suppressed and a different coordination pattern is adopted. Additionally, the duration of partial contralateral disruptions was recorded when left-hand circling velocity ceased $(\omega=0$ for at least $200 \mathrm{msec}$ ) or transiently reversed (e.g., $+\omega$ to $-\omega$ for at least $100 \mathrm{msec}$ ), followed by the resumption of correct left-hand circling. This measure reflects to what extent the performer is able to perform the switch selectively with the right hand while the left hand continues its motion (i.e., division of attention).

\section{MRI data acquisition}

Diffusion tensor images were acquired with a 3-T Magnetom Trio MRI scanner (Siemens, Erlangen, Germany) using the following parameters (Jones and Leemans, 2011): single shot spin-echo; slice thickness $2.9 \mathrm{~mm}$; repetition time $7200 \mathrm{msec}$, echo time $81 \mathrm{msec}$, number of diffusion directions 64 , diffusion weighting $1000 \mathrm{sec} / \mathrm{mm}^{2}$, number of sagittal slices 56 , in-plane resolution $2.2 \times 2.2 \mathrm{~mm}^{2}$ with a field of view of $210 \times 210 \mathrm{~mm}^{2}$.

Moreover, for all subjects a high-resolution T1-weighted structural image was acquired using magnetization prepared rapid gradient echo for anatomical detail (repetition time $2300 \mathrm{msec}$, echo time $2.98 \mathrm{msec}$, in-plane resolution $1 \times 1 \mathrm{~mm}^{2}$ with a field of view of $240 \times 256 \mathrm{~mm}^{2}, 160$ sagittal slices with $1.1 \mathrm{~mm}$ thickness). These structural MRI scans were investigated by an expert neuroradiologist to indicate the location and type of pathology (e.g., shearing or hemorrhage), and identify the degree of diffuse axonal injury (Table 1).

DTI processing. The DTI data were analyzed and processed using the following multi-step procedure: (1) The raw diffusion-weighted data and the non-diffusion-weighted images were loaded into ExploreDTI (Leemans et al., 2009), and we looped through the separate diffusion-weighted imaging volumes at a high frame rate to check for any obvious artifacts in the data, such as large signal dropouts and geometric distortions. Moreover, we inspected the images in different orthogonal views (i.e., not only in the image plane that the data were acquired in) to detect any interslice and intravolume instabilities (e.g., the "zebra pattern"). We also quickly toggled between the views of the first and last acquired diffusion weighted image to observe subtle system drifts. Finally, we checked the residual map (as shown in Fig. 2C), reflecting the difference between the modeled and the measured signal (Tournier et al., 2011). With such a residuals map one can detect artifacts that are not always visible on the FA map or on the individual diffusion-weighted images. (b) The DTI data sets were corrected for subject motion and eddy currentinduced geometric distortions (Leemans and Jones, 2009). In summary, the diffusion-weighted images were realigned to the non-diffusion-weighted image using an affine coregistration method based on mutual information with cubic interpolation to resample the images (Klein et al., 2010). During this correction procedure, the b-matrix was adjusted for the rotational component of subject motion to ensure correct diffusion tensor estimates. (c) The diffusion tensor model was fitted to the data using the Levenberg-Marquardt non-linear regression method (Marquardt, 1963). The diffusion measures FA and axial (AD) and radial diffusivity (RD) were subsequently calculated as described previously (Basser and Pierpaoli, 1996). FA values range from 0 to 1 , where 0 represents maximal isotropic diffusion (i.e., equal amount of diffusion in all directions), or lack of directional organization, and 1 represents maximal anisotropic diffusion (i.e., only movement parallel to the major axis of a WM tract), and higher values reflecting more organized tissues such as in WM tracts. Analyses of axial and radial diffusivity may provide more specific information about the mechanisms that underlie changes in WM following injury (Song et al., 2002, 2005). Axial diffusivity (the first eigenvalue, AD) represents the diffusivity along the first eigenvector, which is assumed to lie parallel with the fiber pathways. Increases in AD are thought to reflect pathology of the axon itself, such as from trauma (Sidaros et al., 2008). Radial diffusivity (average of the second and third eigenvalues) assesses diffusion perpendicular to the main diffusion direction, and appears to be more strongly correlated with myelin abnormalities, either dysmyelination or demyelination (Sidaros et al., 2008). Values of $\mathrm{AD}$ and $\mathrm{RD}$ are positive, with the $\mathrm{AD}$ always larger than the $\mathrm{RD}$ (for regions with FA $>0$ ). (d) We re-inspected the data in three orthogonal planes in a loop format to ensure that the motion/distortion correction was performed correctly, and that no additional artifacts were introduced into the data. (e) DTI data were transformed to MNI space to maximize uniformity in terms of inter-subject brain angulation. In doing so, the subregions of the $\mathrm{CC}$ in the subsequent fiber tractography analysis can be defined in a standardized way. The first step in the DTI co-registration process to MNI space consisted of the construction of a population-based MNI template (Mori et al., 2008; Van Hecke et al., 2008). With this template, an affine, and subsequently a high-dimensional non-affine DTI-based co-registration technique could be applied to obtain the final DTI data sets in MNI space (Leemans et al., 2005; Van Hecke et al., 2007). In the non-affine co-registration approach, the images are modeled as a viscous fluid, imposing a constraint on the local deformation field. During normalization, the Jacobian is constrained to reduce the chance of forcing the underlying brain structures in an anatomically non-plausible way. This viscous fluid model was optimized for aligning multiple diffusion tensor components, and has been applied successfully in a wide range of applications, for which adjusting for morphological inter-subject (and inter-group) differences, such as, for instance, ventricle size, is considered to be of paramount importance (Hecke et al., 2010; Hsu et al., 2010; Sage et al., 2009; Verhoeven et al., 2010). Based on a recently developed simulation framework, the non-affine DTI-based co-registration method, in particular, has been shown to provide highly accurate registration results (Van 


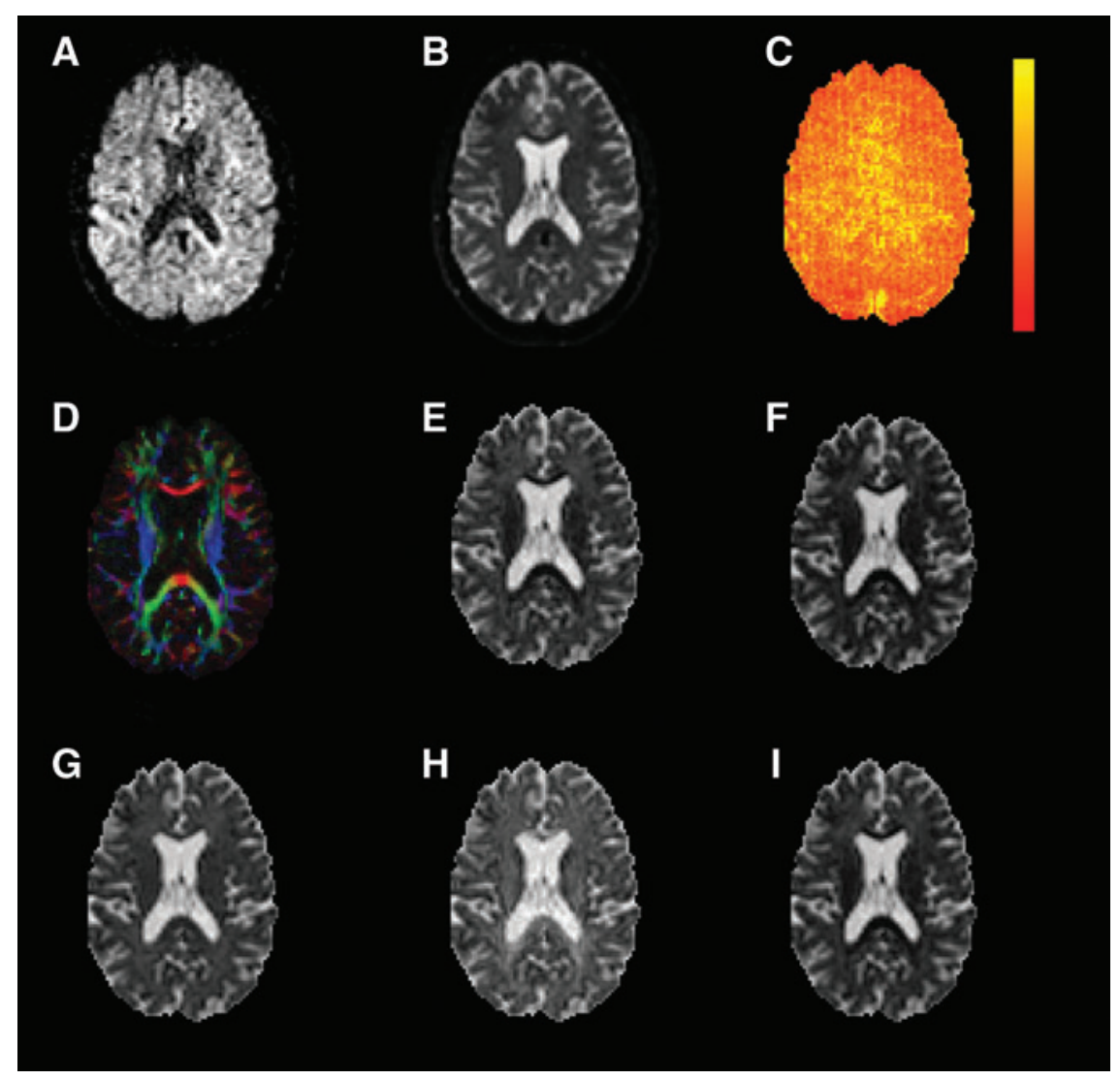

FIG. 2. Axial view of an exemplary diffusion tensor imaging dataset of a traumatic brain injury patient (severity score 2) at the level of the corpus callosum. (A) Diffusion-weighted image. (B) Non-diffusion-weighted image. (C) Diffusion tensor residual map (yellow = high residuals; red=low residuals). (D) Color-coded fractional anisotropy (FA). (E) Second eigenvalue. (F) Third eigenvalue. (G) Mean diffusivity. (H) Axial diffusivity. (I) Radial diffusivity.

Hecke et al., 2009). (f) Deterministic streamline tractography of the CC was performed for each subject by manually drawing regions of interest in ExploreDTI (Leemans et al., 2009) by the same operator (J.G.), who was blinded to the group status of the subjects and the findings of the behavioral tests. FA thresholds to initiate and continue tracking were set to 0.15 ; the maximum angle was thresholded at $40^{\circ}$; and step size was $1 \mathrm{~mm}$. Tractography was performed using twodimensional regions of interest at the midline of the brain. All regions of interest were drawn according to specific anatomical landmarks, and a priori determined rules that were followed carefully and consistently for each subject (Catani and de Thiebaut, 2008). Intra- and inter-rater reliability of this approach have been shown in a previous study in patients with progressive supranuclear palsy (Ito et al., 2008).

Definition of the subregions of the CC. According to the recently described paradigms by Hofer and Frahm (2006) and Huang and associates (2006), the CC was partitioned into seven subregions on the mid-sagittal plane as follows. CC1 was the most anterior segment covering the first sixth of the $\mathrm{CC}$ and containing fibers projecting into the prefrontal cortices. CC2 comprised the remainder of the anterior half of the $\mathrm{CC}$, containing fibers projecting to premotor and supplementary motor cortical areas. CC3 was defined as the posterior half minus the posterior third, comprising fibers projecting into the primary motor cortex. CC4, representing the posterior one-third minus the posterior one-fourth, referred to primary sensory fibers. The most posterior area of the CC, the splenium, was defined as the posterior one-fourth. The splenium was further subdivided into three segments based on the fact that, unlike other segments, the splenium is occupied by three different populations of fibers that connect three different lobes of the brain. These included fibers connecting the parietal lobes (CC5), temporal lobes (CC6), and occipital lobes (CC7). This resulted in a parcellation of the corpus callosum by introducing vertical subdivisions, similar to the Witelson classification (Witelson, 1989), but with respect to the outcome of the fiber tractography. The callosal parietal, temporal, and occipital fiber bundles overlapped and could not be separated by these vertical subdivisions. The resulting callosal parcellations are shown in Figure 3A. Mean values of FA, AD, and RD were obtained from the midsagittal segments only, rather than from the entire CC pathways, as shown in Figure $3 \mathrm{~B}$ and $\mathrm{C}$. In doing so, data contamination originating from crossing fiber areas (or, more generally, partial volume effects) are avoided, fulfilling the assumption of the second-rank diffusion tensor model. Before passing any maps into further analyses, we visualized the color-coded FA, (Fig. 2D), MD (Fig. 2G), AD (Fig. 2H), and RD (Fig. 2I) maps in three orthogonal orientations to check for any obvious artifacts. 


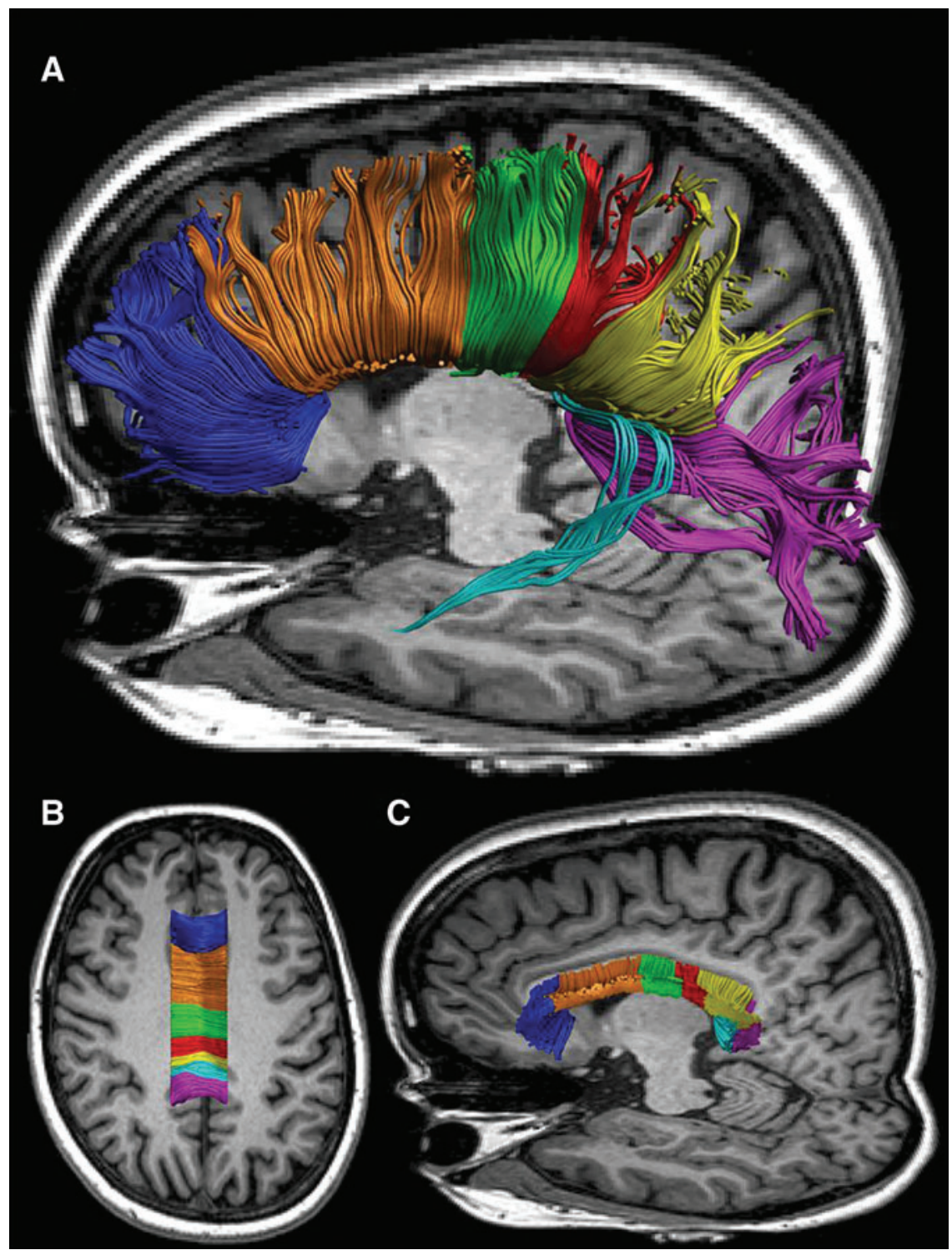

FIG. 3. The corpus callosum (CC) divided into seven subregions and displayed on a 3-D T1 image for a typical control subject: (1) prefrontal region (blue), (2) premotor and supplementary motor region (orange), (3) primary motor region (green), (4) primary sensory region (red), (5) parietal region (yellow), (6) temporal region (magenta), and (7) occipital region (cyan). (A) Sagittal view of all reconstructed callosal fibers comprising bundles projecting into the seven subregions. (B and C) Axial (inferior) and sagittal views of the mid-sagittal fiber bundle segments for each CC subregion. The boundaries of these bundle segments were defined at $1 \mathrm{~cm}$ laterally from the mid-sagittal plane.

\section{Statistical analysis}

For the outcome measures of the clinical tests (Purdue Pegboard Test and TEMPA), two-sample $t$-tests were performed for comparing the TBI group with the control group.

Switch response time and the duration of partial disruptions were subjected to analysis of variance (ANOVA), with the between-subjects factor group (TBI, young), and withinsubject factors resultant pattern (SW-SYMM and SWASYMM), and switch direction of the right hand (CW, CCW).

A multivariate approach to repeated-measures ANOVA was also used to examine microstructural differences among the 7CC regions. The within-subjects factor was CC region with 7 levels; the between-subjects factor included group (TBI versus comparison group). Post-hoc comparisons (Tukey's honestly significant difference) explored between-group differences for each subregion. The dependent variables were FA, AD, and RD.

Stepwise regression analyses were conducted within the TBI group only to assess the contributions of FA to task performance. Clinical measures and instrumented measures of bimanual coordination were entered as the dependent variables. Independent variables included the FA of the 7CC regions. The F-to-enter was 1.0 and the F-to-remove was 0.5 . The resulting standardized regression coefficient $\beta$ (beta) quantified the strength of the association between bimanual task performance and the respective independent variables. 
Finally, the grades of diffuse axonal injury were also used to assess relationships between FA of the 7 CC subregions and severity score. To this end, we applied the Spearman's rank correlation within the TBI group.

All statistical analyses were calculated with Statistica 8 (Statsoft, Inc., Tulsa, OK) using an alpha level of 0.05. Results are reported as mean \pm standard error.

\section{Results}

\section{Clinical tests}

Behaviorally, patients with a history of TBI performed worse on clinical measures of bimanual coordination relative to controls (Fig. 4A and B). There was an effect of group on number of pegs in the bimanual condition of the Purdue Pegboard Test $[t(35)=4.24, p<0.001$; mean for controls: 13 pegs; mean for TBI patients: 11 pegs], and on the summary score for the TEMPA bimanual tasks $[t(36)=-5.81, p<0.001$; mean for controls: $9.72 \mathrm{sec}$; mean for TBI patients: $13.27 \mathrm{sec}]$.

\section{Instrumented task: Bimanual switching}

For right-hand SwRT (Fig. 4C), there were main effects of resultant pattern, with SW-ASYMM trials requiring more time than SW-SYMM trials $[F(1,34)=55.16, p<0.001$; SWASYMM $746 \pm 30 \mathrm{msec}$; SW-SYMM $662 \pm 28 \mathrm{msec}]$, and group, with TBI patients responding more slowly compared with controls $[F(1,34)=8.89, p<0.01$; TBI patients $764 \pm 27 \mathrm{msec}$; controls $645 \pm 29 \mathrm{msec}$. The group effect was not due to differences in movement frequency, as the two groups did not differ in maximal stable frequencies. In other words, both groups moved at equal rates (50\% of individual maximum stable frequency: controls $1.16 \pm 0.02 \mathrm{~Hz}$; TBI $1.15 \pm 0.02 \mathrm{~Hz}$; two-sample $t$-test, $p=0.78)$. No other effects reached significance (notably, there was only one marginally significant interaction effect between the factors resultant pattern and direction, $F(1,34)=3.95, p<0.10)$. For the duration of partial disruptions in the left hand during right hand switch maneuvers (Fig. 4D), there was only a main effect of resultant pattern, with longer disruptions for SW-ASYMM than SWSYMM $[F(1,25)=7.90, p<0.01]$.

\section{Group differences in diffusion tensor imaging measures}

DTI measurements (FA, AD, and RD) obtained for the 7 subregions of the CC are summarized in Figure 5.

Significantly lower FA values were found for the CC subregions in the TBI group compared to controls [group main effect, $F(1,36)=36.43, p<0.001]$. FA differed in different callosal regions [region main effect, $F(6,216)=22.53, p<0.001]$. The significant group $\times$ region interaction $[F(6,216)=5.63, p<0.001]$ revealed that FA was significantly lower in the TBI than in the control group in the prefrontal $(p<0.05)$, primary sensory $(p<0.001)$, and parietal regions $(p<0.001)$. Moreover, analysis of each group separately revealed consistent differences in FA across the CC subregions in the control subjects. Post-hoc comparisons showed that the FA values of the occipital and parietal regions were significantly different than those in all other regions (all $p$ values $<0.01$ ) except for the premotor/supplementary motor region. The highest FA values (approaching 0.8) were observed in the occipital and parietal regions.

For $\mathrm{AD}$, representing diffusivity along the principal diffusion direction (i.e., the first eigenvector of the diffusion
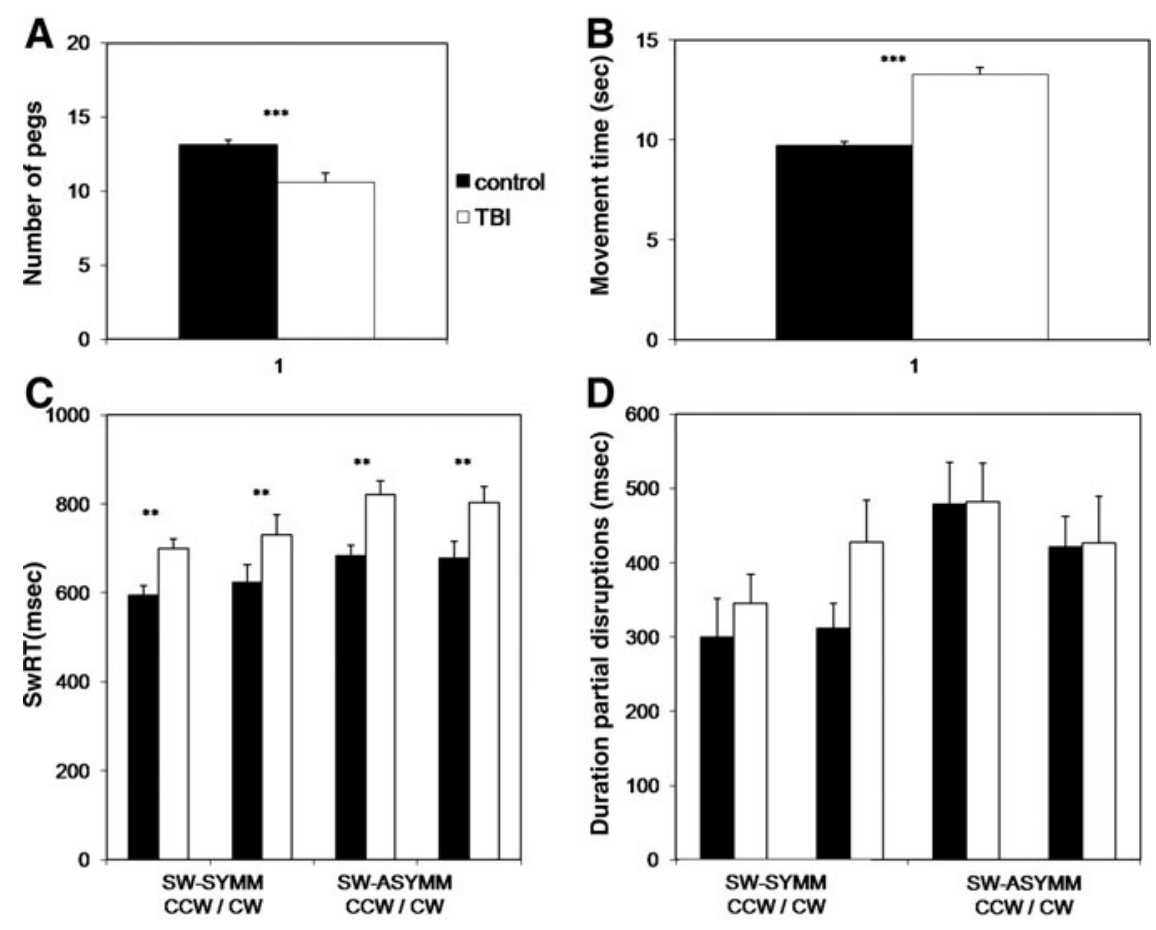

FIG. 4. Behavioral task performance. (A) number of pegs on the Purdue Pegboard Test. (B) Movement time on the TEMPA. (C) Switch response time (SwRT) of the right hand. (D) Duration of partial contralateral disruptions. Within-subjects factors were resultant pattern (switch to symmetric circling, SW-SYMM, or SW-ASYMM, switch to asymmetric circling), and switch direction of the right hand (clockwise, CW, or counter-clockwise, CCW; TBI, white bars; control, black bars; ${ }^{* *} p<0.01$; ${ }^{* * *} p<0.001$ for the TBI group compared to controls; TBI, traumatic brain injury). 

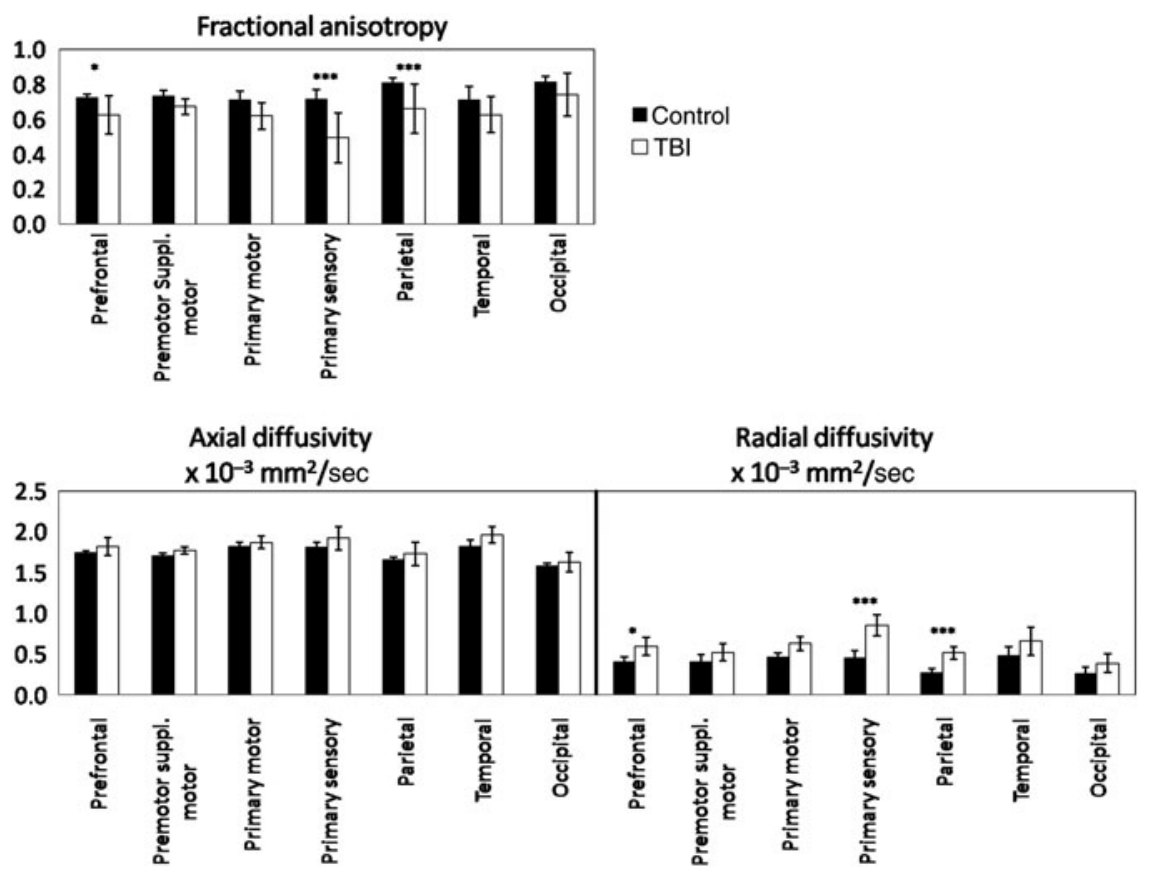

FIG. 5. Diffusion parameters, mean, and standard error (SD) for each corpus callosum region for both groups $\left({ }^{*} p<0.05\right.$, *** $p<0.001$, whereby the TBI group was compared to controls; TBI, traumatic brain injury).

tensor), only the main effects of region $[F(6,216)=50.45$, $p<0.001]$ and group $[F(1,36)=17.84, p<0.001]$ were significant. The AD was significantly higher in TBI patients than controls, but this effect did not vary with region. The significant main effect of region was further examined with a posthoc test (Tukey). The lowest AD values were observed in the parietal and occipital regions. Specifically, the AD of the occipital region was significantly lower than those in all other regions (all $p$ values $<0.001$ ). In addition, the $\mathrm{AD}$ of the parietal subregion was significantly lower than the AD values of the prefrontal, primary motor, primary sensory, and temporal subregions (all $p$ values $<0.001$ ). Finally, differences between the prefrontal and premotor region on the one hand, and the primary motor, primary sensory, and temporal region on the other hand, were also significant (all $p$ values $<0.001$ ).

The RD, a measure of diffusivity perpendicular to the main fiber orientation, showed main effects of region $[F(6,216)=$ 27.86, $p<0.001]$ and group $[F(1,36)=36.24, p<0.001]$. RD was significantly elevated in the TBI versus the control group in the prefrontal $(p<0.05)$, primary sensory $(p<0.001)$, and parietal regions $(p<0.001)$ [interaction group $\times$ region, $F(6,216)=5.50, p<0.001]$. Consequently, it appears that primarily the radial diffusivities were driving the group differences in FA.

In addition, consistently higher standard deviations of the diffusion measures were found for the TBI group relative to controls, demonstrating greater variability in the DTI measures for the TBI group.

\section{Multiple regression analyses}

A series of stepwise multiple regressions were applied to the TBI data with outcome measures of the bimanual coordination tests as dependent variables. Independent variables included the FA of the 7 subregions of the CC. We de- termined which $\mathrm{CC}$ region was related to the bimanual coordination tasks. Because of the minor impact of the type of motor switching task, its four coordination patterns were combined in the subsequent analysis. Moreover, only FA was considered as a DTI metric in these analyses, because it has been suggested to be the most important DTI marker in patients with brain injury (Assaf and Pasternak, 2008; Mori and van Zijl, 2002).

Both outcome variables of the clinical bimanual coordination tests (Purdue Pegboard Test and TEMPA) were significantly correlated with FA of the occipital region, indicating that better bimanual coordination is associated with higher FA values within the occipital region. These models accounted overall for 54\% (TEMPA, $\beta=-0.55, p<0.001$ ) and $61 \%$ (Purdue Pegboard Test, $\beta=0.75, p<0.001$ ) of the variance in performance.

Stepwise multiple regression analyses selected many CC regions as independent variables associated with the switching task. Switch reaction time showed a significant regression with FA of the CC primary sensory region $(\beta=-0.47$, $p<0.05)$. Hence, lower switch response times were associated with a higher WM anisotropy in the primary sensory region. FA of the prefrontal region $(\beta=-0.41, p<0.10)$ was marginally significantly correlated with the switch response times, with higher FA being related to shorter switch reaction times. In addition, a stepwise multiple regression analysis selected FA of the parietal region $(\beta=-0.56, p<0.01)$ as an independent variable, which was negatively associated with the duration of partial contralateral disruptions. In other words, higher FA was associated with shorter contralateral disruptions. It is important to note that the multiple regression analyses were not significant within the control group for both object the manipulation tasks and the cognitive control task. A summary of the regression analyses is shown in Table 2 and Figure 6. 
Table 2. Linear Regression Models Predicting Bimanual Coordination from FA of the CC Subregions

\begin{tabular}{|c|c|c|c|c|c|c|c|c|c|c|c|c|c|c|c|}
\hline \multirow[b]{2}{*}{ Model } & \multirow[b]{2}{*}{$R^{\wedge} 2$} & \multicolumn{2}{|c|}{ Prefrontal } & \multicolumn{2}{|c|}{ Premotor Supplementary motor } & \multicolumn{2}{|c|}{ Primary motor } & \multicolumn{2}{|c|}{ Primary sensory } & \multicolumn{2}{|c|}{ Parietal } & \multicolumn{2}{|c|}{ Temporal } & \multicolumn{2}{|c|}{ Occipital } \\
\hline & & $\beta$ & $\mathrm{p}$ & $\beta$ & $\mathrm{p}$ & $\beta$ & $\mathrm{p}$ & $\beta$ & $\mathrm{p}$ & $\beta$ & $\mathrm{p}$ & $\beta$ & $\mathrm{p}$ & $\beta$ & $\mathrm{p}$ \\
\hline 1 & 0.55 & & & & & & & & & & & & & -0.56 & 0.01 \\
\hline 2 & 0.64 & & & & & & & & & & & & & 0.61 & 0.003 \\
\hline 3 & 0.31 & -0.41 & 0.07 & & & & & -0.47 & 0.05 & & & & & & \\
\hline 4 & 0.41 & & & & & & & & & -0.55 & 0.01 & & & & \\
\hline
\end{tabular}

Each model is referred to with a number in the leftmost column, representing the models: [1] movement time TEMPA; [2] number of pegs Purdue pegboard; [3] switch reaction time; [4] duration partial disruptions.

FA, fractional anisotropy; CC, corpus callosum; TEMPA, Test d'Evaluation de la performance des Membres Superieurs des Personnes Agees.

Interestingly, the severity score (according to Adams et al., 1989) showed a significant correlation with FA of the premotor/supplementary motor region $(r=-0.43, p<0.05)$ and parietal region $(r=-0.48, p<0.05)$. The higher the severity score, the lower the FA value in the premotor/supplementary motor region and parietal region.

\section{Discussion}

This study shows that quantitative DTI information can link the microstructural organization of specific CC substructures and behavioral functions in TBI patients. Bimanual coordination was assessed with a unique set of tasks, spanning daily life object manipulation to cognitive control tasks. First, we will report bimanual coordination deficits in TBI patients. Then WM measures of the 7 specific subregions of the CC will be addressed. Finally, correlations between WM organization of the CC subregions and differential behavioral manifestations of bimanual motor functioning will be discussed.

\section{Bimanual coordination deficits in TBI patients}

TBI patients demonstrated difficulties with bimanual coordination, presenting elevated movement time values during daily life activities, a decreased number of pegs manipulated, and slower response times during the switching task. There is only limited previous evidence of impaired bimanual coordination performance following TBI, despite the fact that slowing of motor functions is a frequent clinical outcome in these patients (Levin et al., 1990). Congruent with our results, earlier studies showed deficits in upper-limb speed and dexterity in children after TBI with the BruininksOseretsky Test of Motor Proficiency (Chaplin et al., 1993; Wallen et al., 2001), and pegboard tasks (Bowen et al., 1997). However, these studies focused on childhood TBI. In a study by Asikainen and associates (1999), the Purdue Pegboard Test also differentiated between TBI patients with good and moderate or severe disability (according to the Glasgow Outcome Scale score) at the end of the follow-up, and
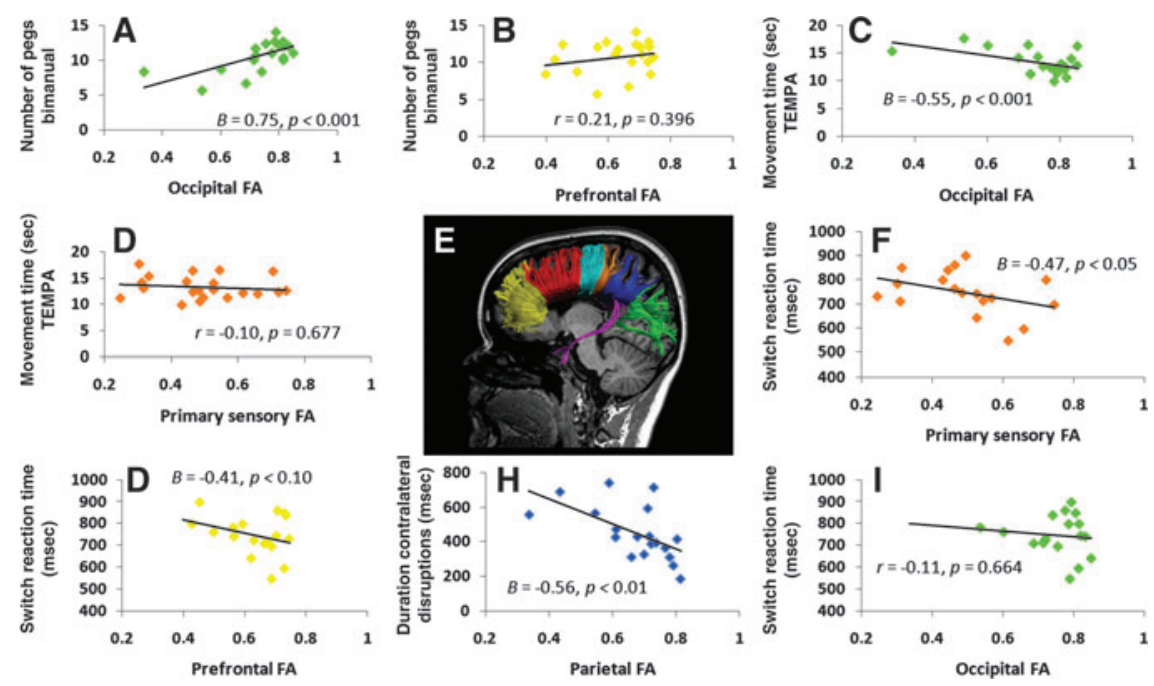

FIG. 6. Plots indicating the relationships between the behavioral task scores and fractional anisotropy (FA) of specific corpus callosum (CC) subregions. Whereas FA in commissural pathways between occipital areas played a role in performance on the clinical tests of bimanual coordination $(\mathbf{A}-\mathbf{C})$, deficits in the switching task were related to disrupted interhemispheric communication in the prefrontal, sensory, and parietal regions $(\mathbf{F}-\mathbf{H})$. The clinical tests of bimanual coordination did not correlate significantly with FA of the prefrontal (B), primary sensory (D), and parietal subregions, neither did FA of the occipital CC subregion with switching task performance (I). (E) The sagittal view of the CC is divided into seven subregions: (1) prefrontal region (yellow), (2) premotor and supplementary motor region (red), (3) primary motor region (cyan), (4) primary sensory region (orange), (5) parietal region (blue), (6) temporal region (magenta), and (7) occipital region (green). Color image is available online at www.liebertpub.com/neu 
predicted incapacity for employment (i.e., those with worse outcomes being slower).

The kinematic results of the cognitive control task showed that switching to the more difficult asymmetric movement pattern required more time, and resulted in more contralateral disruptions than when the switch resulted in symmetric movements. These and other facets of rhythmic bimanual coordination dynamics have been reported in normal subjects (Byblow et al., 1999, 2000; Wenderoth and Weigelt, 2009). Here we extend these observations by exemplifying more pronounced cognitive control deficits in the TBI patients. The patient group took longer to implement pattern change via the right hand than the control subjects. These results are consistent with previous studies using different cognitive task-switching paradigms in TBI (Larson et al., 2006; Schroeter et al., 2007). These switching deficits in TBI patients may be related to attentional problems when transferring between different motor tasks (Park et al., 2009). In other words, patients with TBI have difficulty shifting attention in order to perform on-line modification of motor patterns during the execution of complex movements.

To summarize, this general slowing in switching among bimanual coordination patterns supports the notion that the monitoring of speed-associated movement parameters may be useful to trace the course of restitution of motor function during rehabilitation in TBI patients.

\section{Group differences in diffusion tensor imaging}

We found that mean FA in several subregions of the CC was lower in a young group suffering from moderate-tosevere TBI when compared with a control group that was matched for demographic variables. These findings extend those of previous pediatric and adult DTI studies showing WM disruption in the CC following TBI (Chan et al., 2003; Ewing-Cobbs et al., 2006, 2008; Huisman et al., 2004; Kraus et al., 2007; Rutgers et al., 2008; Wilde et al., 2006; Wozniak et al., 2007). However, in contrast to previous work only addressing three subregions of the CC or using the Witelson classification, we explored the microstructural organization of 7 single regions of interest using a fine-tuned parcellation method with anatomical/functional relevance.

First, we demonstrated significantly lower FA in the prefrontal subregion of the CC of our TBI patients compared with controls. Alteration of this DTI metric in the genu suggests impaired tissue organization of prefrontal and frontal fibers involved in motor planning and in regulating cognition and emotion (Levin et al., 2004; Max et al., 2005). The primary sensory subregion was also affected in the TBI group, compromising the interhemispheric transfer of sensory information. Recently, there have been a few DTI investigations of possible involvement of the sensory pathways in the pathogenesis of motor deficits in TBI (Caeyenberghs et al., 2010a, 2010b). Specifically, decreased FA was found in the TBI group in dedicated pathways involved in the transmission of afferent information, such as the posterior thalamic radiation. Finally, we found FA to be decreased in the parietal subregion of the CC.

To further specify the observed microstructural diffusion changes in TBI patients, we also examined the axial (AD) and radial (RD) diffusivity parameters. Changes in RD in the absence of changes in AD have been associated with changes in myelin structure (Beaulieu, 2002; Song et al., 2002), whereas changes in $\mathrm{AD}$ in the absence of changes in $\mathrm{RD}$ have been related to an increase in axon diameter (Dougherty et al., 2007). Here we found that the increase in diffusivity was distributed across both AD and RD. This pattern differs from acute animal models of axonal injury and demyelination. For example, 12 weeks of cuprizone treatment in the mouse resulted in demyelination and produced a decrease in AD followed by an increase in RD in the CC (Sun et al., 2006). The decrease in AD was transient and had fully recovered at the time the increase in $\mathrm{RD}$ occurred. The cause of this decrease in the acute mouse model might be transient extra-axonal processes inhibiting or disrupting linear water motility (e.g., inflammation and cytotoxic edema). Similar results were found in studies by Mac Donald and colleagues (2007a, 2007b). They observed reductions in FA and increases in AD in the first few hours after a cortical contusion in experimental models of TBI, and these early changes reflected axonal damage (Song et al., 2002). One to 4 weeks after trauma, FA values remained decreased, whereas axial diffusivity "pseudo-normalized" and radial diffusivity increased. Furthermore, in a longitudinal study in TBI adults a decrease of FA was found in all investigated WM regions in the late subacute stage ( \pm 8 weeks post-injury), due to decreased AD and increased RD (Sidaros et al., 2008).

In the case of our chronic TBI patients, we observed increases in both AD and RD, which could be explained by decreased axonal packing within a voxel, allowing for increased diffusivity in all orientations. An increase in extra-axonal fluid could be due to thinning of myelin or a decrease in axonal diameter or both. The possibility of thinning of myelin is supported by the observation that the increase in diffusivity of the CC was more apparent in RD than AD. Kraus and colleagues (2007) found similar changes in TBI adults with the average time from injury being 10 years. Our findings are also consistent with a recent pediatric TBI study (Ewing-Cobbs et al., 2008) showing a significant reduction in FA and increased RD in the genu (prefrontal), posterior midbody (primary motor), isthmus (primary sensory), and splenium (parietal, temporal, and occipital) in 41 children and adolescents with TBI.

It is important to note that the measured FA distribution in the controls is in general agreement with previous studies using DTI (Chepuri et al., 2002; Madden et al., 2004), or light/ electron microscopy techniques in post-mortem brains (Aboitz et al., 1992). For example, Aboitiz and associates (1992) revealed a consistent pattern of regional differentiation of fiber types in the CC: thin, largely unmyelinated and densely packed fibers were present predominantly in the genu and splenium of the CC. In contrast, larger-diameter, myelinated, and less densely packed fibers were concentrated in the posterior midbody of the CC (i.e., the primary motor region). This regional differentiation of fiber types and densities is paralleled by a regional differentiation of FA, with higher values where thin densely packed CC fibers predominate (Hofer and Frahm, 2006). These structural differences are in line with the observation of the lowest FA values in the primary motor/sensory areas and temporal subregions, and the highest FA values in the occipital fiber bundle.

\section{Structural organization of the corpus callosum and its relation to bimanual coordination}

Our study is the first to identify relations of DTI metrics with bimanual coordination in TBI patients in the context of 
clinical and instrumented tests. Regional callosal FA values showed striking differential relationships with specific bimanual coordination tasks, as discussed next.

First, performance on the Purdue Pegboard Test and TEMPA was significantly related to FA within the occipital regions of the $\mathrm{CC}$, indicating that individual differences in the occipital subregion directly accounted for performance variation on these clinical tests of bimanual coordination. It is noteworthy that both the TEMPA and the Purdue Pegboard Test involve precise manual control based on on-line processing of visual information. The splenium has known projections to the occipital areas of the brain, which represent an important medium for visual information processing. Our finding is consistent with a previous report in individuals with human immunodeficiency virus that also revealed the CC splenium to be a significant independent variable of speed of fine finger movements and grooved pegboard performance (Pfefferbaum et al., 2007). In another study, higher FA in the splenium of children with TBI was again associated with faster interference resolution on an inhibition task, which involved processing of visual information (Wilde et al., 2006). Accordingly, it appears that disruptions in commissural pathways between occipital areas plays a limiting role in the performance on the visuomotor TEMPA and Purdue Pegboard Tests in these TBI patients.

Second, the regression analyses provided evidence that deficits in motor task switching are related to disrupted interhemispheric communication in the prefrontal, sensory, and parietal areas. This is consistent with the notion that switching is a complex task based on a distributed parietofrontal network of brain areas (see Coxon et al., 2010 for elaboration of the functional activations associated with this task). Parietal participation in the switching task is in accordance with the proposal that spatial aspects of directionally incompatible movements are integrated in the parietal cortex (Wenderoth et al., 2004, 2005b). Furthermore, it was found that coordination of directional information between the hands is abandoned by posterior callosotomy (Eliassen et al., 1999).

Third, the motor switching task was also marginally correlated with FA of the prefrontal CC subregion. Other studies also identified significant relations between motor task performance and FA in the genu. For example, Bonzano and colleagues (2008) found that bimanual coordination performance in patients with multiple sclerosis was mainly linked with white matter organization of the anterior part of the CC (regions 1 and 2). Similar results were obtained in another study showing that visuomotor interhemispheric transfer was best predicted by mean diffusivity in the genu of alcoholics (Schulte et al., 2005). The switching task in our study required flexible adjustments of motor behavior and adaptations to sudden environmental contingencies, which are an expression of executive functioning (Gilbert and Burgess, 2008). Moreover, the functional MRI activations involved in motor task switching (Coxon et al., 2010), including the dorsolateral prefrontal cortex and superior/inferior parietal lobes, are consistent with our finding of a relation between improved performance on the switching task and higher FA in the parietal and prefrontal regions.

Finally, performance on the motor switching task was also significantly correlated with FA in the primary sensory regions. Higher FA within the primary sensory region was as- sociated with shorter contralateral disruptions, evidencing more successful switching behavior.

Several limitations in our current study must be identified. One issue requiring further consideration is the impact of general ability. An alternative strategy for future studies might be to match the control subjects according to level of education or general ability. Furthermore, longitudinal studies are needed to determine how changes in DTI parameters of the CC are related to general functional outcome, including measures of bimanual coordination. For example, Wang and colleagues (2008) found that DTI measurements of the anterior body and splenium of the CC at the acute stage of injury showed strong correlations with the Glasgow Outcome ScaleExtended scores. Such longitudinal designs would also be beneficial to tackle potential confounds, such as partial volume effect-related covariates that can modulate the diffusion measures (Vos et al., 2011).

In summary, this is the first report applying a new partitioning method for the CC in TBI patients. We have found a reduction in FA and increased RD in the prefrontal, primary sensory, and parietal regions, which suggests disruption in interhemispheric tracts connecting primary sensory fibers and fibers coursing through the prefrontal and posterior parietal regions. Disruption in these pathways is associated with significant bimanual coordination deficits observed in the TBI patients. Interestingly, distinct callosal subregions are independently associated with specific bimanual coordination maneuvers spanning the continuum from clinical (manual abilities) to laboratory (cognitive control) in a meaningful task-specific manner. These brain-behavior relations pave the way for DTI-based biomarkers to improve TBI diagnostics/ prognosis, and for follow-up of motor deficits.

\section{Acknowledgments}

Support for this study was provided through a grant from the Research Programme of the Research Foundation Flanders (FWO) (Levenslijn \# G.0482.010), and grant P6/29 from the Interuniversity Attraction Poles program of the Belgian federal government. K. Caeyenberghs is funded by a post-doctoral fellowship of the FWO.

\section{Author Disclosure Statement}

No competing financial interests exist.

\section{References}

Aboitiz, F., Scheibel, A.B., Fisher, R.S., and Zaidel, E. (1992). Fiber composition of the human corpus callosum. Brain Res. 598, 143-153.

Adams, J.H., Doyle, D., Ford, I., Gennarelli, T.A., Graham, D.I., and McLellan, D.R. (1989). Diffuse axonal injury in head injury: definition, diagnosis and grading. Histopathology 15, 49-59.

Asikainen, I., Nybo, T., Muller, K., Sarna, S., and Kaste, M. (1999). Speed performance and long-term functional and vocational outcome in a group of young patients with moderate or severe traumatic brain injury. Eur. J. Neurol. 6, 179-185.

Assaf, Y., and Pasternak, O. (2008). Diffusion tensor imaging (DTI)-based white matter mapping in brain research: a review. J. Mol. Neurosci. 34, 51-61.

Basser, P.J., and Pierpaoli, C. (1996). Microstructural and physiological features of tissues elucidated by quantitative-diffusiontensor MRI. J. Magn. Reson. B 111, 209-219. 
Beaulieu, C. (2002). The basis of anisotropic water diffusion in the nervous system-a technical review. NMR Biomed. 15, 435-455.

Behrens, T.E., Johansen-Berg, H., Woolrich, M.W., Smith, S.M., Wheeler-Kingshott, C.A., Boulby, P.A., Barker, G.J., Sillery, E.L., Sheehan, K., Ciccarelli, O., Thompson, A.J., Brady, J.M., and Matthews, P.M. (2003). Non-invasive mapping of connections between human thalamus and cortex using diffusion imaging. Nat. Neurosci. 6, 750-757.

Bonzano, L., Tacchino, A., Roccatagliata, L., Abbruzzese, G., Mancardi, G.L., and Bove, M. (2008). Callosal contributions to simultaneous bimanual finger movements. J. Neurosci. 28, 3227-3233.

Bowen, J.M., Clark, E., Bigler, E.D., Gardner, M., Nilsson, D., Gooch, J., and Pompa, J. (1997). Childhood traumatic brain injury: neuropsychological status at the time of hospital discharge. Dev. Med. Child Neurol. 39, 17-25.

Byblow, W.D., Lewis, G.N., Stinear, J.W., Austin, N.J., and Lynch, M. (2000). The subdominant hand increases in the efficacy of voluntary alterations in bimanual coordination. Exp. Brain Res. 131, 366-374.

Byblow, W.D., Summers, J.J., Lewis, G.N., and Thomas, J. (2002). Bimanual coordination in Parkinson's disease: deficits in movement frequency, amplitude, and pattern switching. Mov. Disord. 17, 20-29.

Byblow, W.D., Summers, J.J., Semjen, A., Wuyts, I.J., and Carson, R.G. (1999). Spontaneous and intentional pattern switching in a multisegmental bimanual coordination task. Motor Control 3, 372-393.

Caeyenberghs, K., Leemans, A., Geurts, M., Taymans, T., Vanderlinden C., Smits-Engelsman, B.C., Sunaert, S., and Swinnen, S.P. (2010a). Brain-behavior relationships in young traumatic brain injury patients: fractional anisotropy measures are highly correlated with dynamic visuomotor tracking performance. Neuropsychologia 48, 1472-1482.

Caeyenberghs, K., Leemans, A., Geurts, M., Taymans, T., Vanderlinden C., Smits-Engelsman, B.C., Sunaert, S., and Swinnen, S.P. (2010b). Brain-behavior relationships in young traumatic brain injury patients: DTI metrics are highly correlated with postural control. Hum. Brain Mapp. 31, 992-1002.

Carson, R.G., Thomas, J., Summers, J.J., Walters, M.R., and Semjen, A. (1997). The dynamics of bimanual circle drawing. Q. J. Exp. Psychol. A 50, 664-683.

Catani, M., and de Thiebaut, S.M. (2008). A diffusion tensor imaging tractography atlas for virtual in vivo dissections. Cortex 44, 1105-1132.

Chan, J.H., Tsui, E.Y., Peh, W.C., Fong, D., Fok, K.F., Leung, K.M., Yuen, M.K., and Fung, K.K. (2003). Diffuse axonal injury: detection of changes in anisotropy of water diffusion by diffusion-weighted imaging. Neuroradiology 45, 34-38.

Chaplin, D., Deitz, J., and Jaffe, K.M. (1993). Motor performance in children after traumatic brain injury. Arch. Phys. Med. Rehabil. 74, 161-164.

Chepuri, N.B., Yen, Y.F., Burdette, J.H., Li, H., Moody, D.M., and Maldjian, J.A. (2002). Diffusion anisotropy in the corpus callosum. AJNR Am. J. Neuroradiol. 23, 803-808.

Cicerone, K.D., Dahlberg, C., Malec, J.F., Langenbahn, D.M., Felicetti, T., Kneipp, S., Ellmo, W., Kalmar, K., Giacino, J.T., Harley, J.P., Laatsch, L., Morse, P.A., and Catanese, J. (2005). Evidence-based cognitive rehabilitation: updated review of the literature from 1998 through 2002. Arch. Phys. Med. Rehabil. 86, 1681-1692.

Coxon, J.P., Goble, D.J., Van, I.A., De, V.J., Wenderoth, N., and Swinnen, S.P. (2010). Reduced basal ganglia function when elderly switch between coordinated movement patterns. Cereb. Cortex 20, 2368-2379.

Debaere, F., Wenderoth, N., Sunaert, S., and Swinnen, S.P. (2004). Cerebellar and premotor function in bimanual coordination: parametric neural responses to spatiotemporal complexity and cycling frequency. Neuroimage 21, 1416-1427.

Deiber, M.P., Caldara, R., Ibanez, V., and Hauert, C.A. (2001). Alpha band power changes in unimanual and bimanual sequential movements, and during motor transitions. Clin. Neurophysiol. 112, 1419-1435.

Desrosiers, J., Hebert, R., Bravo, G., and Dutil, E. (1995b). The Purdue Pegboard Test: normative data for people aged 60 and over. Disabil. Rehabil. 17, 217-224.

Desrosiers, J., Hebert, R., Bravo, G., and Dutil, E. (1995a). Upper extremity performance test for the elderly (TEMPA): normative data and correlates with sensorimotor parameters. Test d'Evaluation des Membres Superieurs de Personnes Agees. Arch. Phys. Med. Rehabil. 76, 1125-1129.

Dougherty, R.F., Ben-Shachar, M., Deutsch, G.K., Hernandez, A., Fox, G.R., and Wandell, B.A. (2007). Temporal-callosal pathway diffusivity predicts phonological skills in children. Proc. Natl. Acad. Sci. USA 104, 8556-8561.

Eliassen, J.C., Baynes, K., and Gazzaniga, M.S. (2000). Anterior and posterior callosal contributions to simultaneous bimanual movements of the hands and fingers. Brain 123, 2501-2511.

Eliassen, J.C., Baynes, K., and Gazzaniga, M.S. (1999). Direction information coordinated via the posterior third of the corpus callosum during bimanual movements. Exp. Brain Res. 128, 573-577.

Ewing-Cobbs, L., Hasan, K.M., Prasad, M.R., Kramer, L., and Bachevalier, J. (2006). Corpus callosum diffusion anisotropy correlates with neuropsychological outcomes in twins disconcordant for traumatic brain injury. AJNR Am. J. Neuroradiol. 27, 879-881.

Ewing-Cobbs, L., Prasad, M.R., Swank, P., Kramer, L., Cox, C.S., Jr., Fletcher, J.M., Barnes, M., Zhang, X., and Hasan, K.M. (2008). Arrested development and disrupted callosal microstructure following pediatric traumatic brain injury: relation to neurobehavioral outcomes. Neuroimage 42, 1305-1315.

Feys, P., Duportail, M., Kos, D., Van, A.P., and Ketelaer, P. (2002). Validity of the TEMPA for the measurement of upper limb function in multiple sclerosis. Clin. Rehabil. 16, 166-173.

Gilbert, S.J., and Burgess, P.W. (2008). Executive function. Curr. Biol. 18, R110-R114.

Hecke, W.V., Nagels, G., Leemans, A., Vandervliet E., Sijbers, J., and Parizel, P.M. (2010). Correlation of cognitive dysfunction and diffusion tensor MRI measures in patients with mild and moderate multiple sclerosis. J Magn Reson Imaging. 31, 1492-1498.

Higgins, J., Salbach, N.M., Wood-Dauphinee, S., Richards, C.L., Côté, R., and Mayo, N.E. (2006). The effect of a task-oriented intervention on arm function in people with stroke: a randomized controlled trial. Clin Rehabil. 20, 296-310.

Hofer, S., and Frahm, J. (2006). Topography of the human corpus callosum revisited-comprehensive fiber tractography using diffusion tensor magnetic resonance imaging. Neuroimage 32, 989-994.

Hsu, J.L., Van, H.W., Bai, C.H., Lee, C.H., Tsai, Y.F., Chiu, H.C., Jaw, F.S., Hsu, C.Y., Leu, J.G., Chen, W.H., and Leemans, A. (2010). Microstructural white matter changes in normal aging: a diffusion tensor imaging study with higher-order polynomial regression models. Neuroimage 49, 32-43.

Huang, L., Ling, X.Y., and Liu, S.R. (2006). Diffusion tensor imaging on white matter in normal adults and elderly patients with hypertension. Chin. Med. J. (Engl.) 119, 1304-1307. 
Huisman, T.A., Schwamm, L.H., Schaefer, P.W., Koroshetz, W.J., Shetty-Alva, N., Ozsunar, Y., Wu, O., and Sorensen, A.G. (2004). Diffusion tensor imaging as potential biomarker of white matter injury in diffuse axonal injury. AJNR Am. J. Neuroradiol. 25, 370-376.

Immisch, I., Waldvogel, D., and Hallett, M. (2001). The role of the medial wall and its anatomical variations for bimanual antiphase and in-phase movements. Neuroimage 14, 674-684.

Ito, S., Makino, T., Shirai, W., and Hattori, T. (2008). Diffusion tensor analysis of corpus callosum in progressive supranuclear palsy. Neuroradiology 50, 981-985.

Jancke, L., Himmelbach, M., Shah, N.J., and Zilles, K. (2000a). The effect of switching between sequential and repetitive movements on cortical activation. Neuroimage 12, 528-537.

Jancke, L., Peters, M., Himmelbach, M., Nosselt, T., Shah, J., and Steinmetz, H. (2000b). fMRI study of bimanual coordination. Neuropsychologia 38, 164-174.

Johansen-Berg, H., la-Maggiore, V., Behrens, T.E., Smith, S.M., and Paus, T. (2007). Integrity of white matter in the corpus callosum correlates with bimanual co-ordination skills. Neuroimage 36 Suppl. 2, T16-T21.

Jones, D.K., and Leemans, A. (2011). Diffusion tensor imaging. Methods Mol. Biol. 711, 127-144.

Kermadi, I., Liu, Y., and Rouiller, E.M. (2000). Do bimanual motor actions involve the dorsal premotor (PMd), cingulate (CMA) and posterior parietal (PPC) cortices? Comparison with primary and supplementary motor cortical areas. Somatosens. Mot. Res. 17, 255-271.

Klein, S., Staring, M., Murphy, K., Viergever, M.A., and Pluim, J.P. (2010). Elastix: a toolbox for intensity-based medical image registration. IEEE Trans. Med. Imaging 29, 196-205.

Kraus, M.F., Susmaras, T., Caughlin, B.P., Walker, C.J., Sweeney, J.A., and Little, D.M. (2007). White matter integrity and cognition in chronic traumatic brain injury: a diffusion tensor imaging study. Brain 130, 2508-2519.

Kuhtz-Buschbeck, J.P., Hoppe, B., Golge, M., Dreesmann, M., Stunitz, U., and Ritz, A. (2003a). Sensorimotor recovery in children after traumatic brain injury: analyses of gait, gross motor, and fine motor skills. Dev. Med. Child Neurol. 45, 821828.

Kuhtz-Buschbeck, J.P., Stolze, H., Golge, M., and Ritz, A. (2003b). Analyses of gait, reaching, and grasping in children after traumatic brain injury. Arch. Phys. Med. Rehabil. 84, 424-430.

Larson, E.B., Burnison, D.S., and Brown, W.S. (2002). Callosal function in multiple sclerosis: bimanual motor coordination. Cortex 38, 201-214.

Larson, M.J., Perlstein, W.M., Demery, J.A., and Stigge-Kaufman, D.A. (2006). Cognitive control impairments in traumatic brain injury. J. Clin. Exp. Neuropsychol. 28, 968-986.

Leemans, A., Sijbers, J., De Backer, S., Vandervliet, E., and Parizel, P.M. (2005). Affine coregistration of diffusion tensor magnetic resonance images using mutual information. Lecture notes in computer science, 3708, 523-530.

Leemans, A., and Jones, D.K. (2009). The B-matrix must be rotated when correcting for subject motion in DTI data. Magn. Reson. Med. 61, 1336-1349.

Leemans, A., Jeurissen, B., Sijbers, J., and Jones, D.K. (2009). ExploreDTI: a graphical toolbox for processing, analyzing, and visualizing diffusion MR data, in: 17th Annual Meeting of Intl. Soc. Mag. Reson. Med., Hawaii, p. 3537.

Levin, H.S., Gary, H.E., Jr., Eisenberg, H.M., Ruff, R.M., Barth, J.T., Kreutzer, J., High, W.M., Jr., Portman, S., Foulkes, M.A., and Jane, J.A. (1990). Neurobehavioral outcome 1 year after severe head injury. Experience of the Traumatic Coma Data Bank. J. Neurosurg. 73, 699-709.

Levin, H.S., Hanten, G., Zhang, L., Swank, P.R., Ewing-Cobbs, L., Dennis, M., Barnes, M.A., Max, J., Schachar, R., Chapman, S.B., and Hunter, J.V. (2004). Changes in working memory after traumatic brain injury in children. Neuropsychology 18, 240-247.

Mac Donald, C.L., Dikranian, K., Bayly, P., Holtzman, D., and Brody, D. (2007a). Diffusion tensor imaging reliably detects experimental traumatic axonal injury and indicates approximate time of injury. J. Neurosci. 27, 11869-11876.

Mac Donald, C.L., Dikranian, K., Song, S.K., Bayly, P.V., Holtzman, D.M., and Brody, D.L. (2007b). Detection of traumatic axonal injury with diffusion tensor imaging in a mouse model of traumatic brain injury. Exp. Neurol. 205, 116-131.

Madden, D.J., Whiting, W.L., Huettel, S.A., White, L.E., MacFall, J.R., and Provenzale, J.M. (2004). Diffusion tensor imaging of adult age differences in cerebral white matter: relation to response time. Neuroimage 21, 1174-1181.

Marquardt, D.W. (1963). An algorithm for least-squares estimation of nonlinear parameters. SIAM J. Appl. Math. 11, 431441.

Max, J.E., Schachar, R.J., Levin, H.S., Ewing-Cobbs, L., Chapman, S.B., Dennis, M., Saunders, A., and Landis, J. (2005). Predictors of secondary attention-deficit/hyperactivity disorder in children and adolescents 6 to 24 months after traumatic brain injury. J. Am. Acad. Child Adolesc. Psychiatry 44, 10411049.

Mori, S., and van Zijl, P.C. (2002). Fiber tracking: principles and strategies - a technical review. NMR Biomed. 15, 468-480.

Mori, S., Oishi, K., Jiang, H., Jiang, L., Li, X., Akhter, K., Hua, K., Faria, A.V., Mahmood, A., Woods, R., Toga, A.W., Pike, G.B., Neto, P.R., Evans, A., Zhang, J., Huang, H., Miller, M.I., and Mazziotta, J. (2008). Stereotaxic white matter atlas based on diffusion tensor imaging in an ICBM template. Neuroimage 40, 570-582.

Moseley, A.M., and Yap, M.C. (2003). Interrater reliability of the TEMPA for the measurement of upper limb function in adults with traumatic brain injury. J. Head Trauma Rehabil. 18, 526531.

Muetzel, R.L., Collins, P.F., Mueller, B.A., Schissel, M., Lim, K.O., and Luciana, M. (2008). The development of corpus callosum microstructure and associations with bimanual task performance in healthy adolescents. Neuroimage 39, 19181925.

Oldfield, R.C. (1971). The assessment and analysis of handedness: the Edinburgh inventory. Neuropsychologia 9, 97-113.

Park, B.S., Allen, D.N., Barney, S.J., Ringdahl, E.N., and Mayfield, J. (2009). Structure of attention in children with traumatic brain injury. Appl. Neuropsychol. 16, 1-10.

Pfefferbaum, A., Rosenbloom, M.J., Adalsteinsson, E., and Sullivan, E.V. (2007). Diffusion tensor imaging with quantitative fibre tracking in HIV infection and alcoholism comorbidity: synergistic white matter damage. Brain 130, 48-64.

Platz, T., Winter, T., Muller, N., Pinkowski, C., Eickhof, C., and Mauritz, K.H. (2001). Arm ability training for stroke and traumatic brain injury patients with mild arm paresis: a singleblind, randomized, controlled trial. Arch. Phys. Med. Rehabil. 82, 961-968.

Powell, K.B., and Voeller, K.K. (2004). Prefrontal executive function syndromes in children. J. Child Neurol. 19, 785-797.

Rees, L., Marshall, S., Hartridge, C., Mackie, D., and Weiser, M. (2007). Cognitive interventions post acquired brain injury. Brain Inj. 21, 161-200. 
Rossi, C., and Sullivan, S.J. (1996). Motor fitness in children and adolescents with traumatic brain injury. Arch. Phys. Med. Rehabil. 77, 1062-1065.

Rutgers, D.R., Fillard, P., Paradot, G., Tadie, M., Lasjaunias, P., and Ducreux, D. (2008). Diffusion tensor imaging characteristics of the corpus callosum in mild, moderate, and severe traumatic brain injury. AJNR Am. J. Neuroradiol. 29, 17301735.

Rutgers, D.R., Toulgoat, F., Cazejust, J., Fillard, P., Lasjaunias, P., and Ducreux, D. (2008). White matter abnormalities in mild traumatic brain injury: a diffusion tensor imaging study. AJNR Am. J. Neuroradiol. 29, 514-519.

Sadato, N., Ibanez, V., Campbell, G., Deiber, M.P., Le Bihan, D., and Hallett, M. (1997b). Frequency-dependent changes of regional cerebral blood flow during finger movements: functional MRI compared to PET. J. Cereb. Blood Flow Metab. 17, 670-679.

Sadato, N., Yonekura, Y., Waki, A., Yamada, H., and Ishii, Y. (1997a). Role of the supplementary motor area and the right premotor cortex in the coordination of bimanual finger movements. J. Neurosci. 17, 9667-9674.

Sage, C.A., Van, H.W., Peeters, R., Sijbers, J., Robberecht, W., Parizel, P., Marchal, G., Leemans, A., and Sunaert, S. (2009). Quantitative diffusion tensor imaging in amyotrophic lateral sclerosis: revisited. Hum. Brain Mapp. 30, 3657-3675.

Schroeter, M.L., Ettrich, B., Schwier, C., Scheid, R., Guthke, T., and von Cramon, D.Y. (2007). Diffuse axonal injury due to traumatic brain injury alters inhibition of imitative response tendencies. Neuropsychologia 45, 3149-3156.

Schulte, T., Sullivan, E.V., Muller-Oehring, E.M., Adalsteinsson, E., and Pfefferbaum, A. (2005). Corpus callosal microstructural integrity influences interhemispheric processing: a diffusion tensor imaging study. Cereb. Cortex 15, 1384-1392.

Serrien, D.J., Nirkko, A.C., and Wiesendanger, M. (2001). Role of the corpus callosum in bimanual coordination: a comparison of patients with congenital and acquired callosal damage. Eur. J. Neurosci. 14, 1897-1905.

Sidaros, A., Engberg, A.W., Sidaros, K., Liptrot, M.G., Herning, M., Petersen, P., Paulson, O.B., Jernigan, T.L., and Rostrup, E. (2008). Diffusion tensor imaging during recovery from severe traumatic brain injury and relation to clinical outcome: a longitudinal study. Brain 131, 559-572.

Song, S.K., Sun, S.W., Ramsbottom, M.J., Chang, C., Russell, J., and Cross, A.H. (2002). Dysmyelination revealed through MRI as increased radial (but unchanged axial) diffusion of water. NeuroImage 17, 1429-1436.

Song, S.K., Yoshino, J., Le, T.Q., Lin, S.J., Sun, S.W., Cross, A.H., and Armstrong, R.C. (2005). Demyelination increases radial diffusivity in corpus callosum of mouse brain. Neuroimage 26, 132-140.

Stephan, K.M., Binkofski, F., Halsband, U., Dohle, C., Wunderlich, G., Schnitzler, A., Tass, P., Posse, S., Herzog, H., Sturm, V., Zilles, K., Seitz, R.J., and Freund, H.J. (1999b). The role of ventral medial wall motor areas in bimanual co-ordination. A combined lesion and activation study. Brain 122, 351-368.

Stephan, K.M., Binkofski, F., Posse, S., Seitz, R.J., and Freund, H.J. (1999a). Cerebral midline structures in bimanual coordination. Exp. Brain Res. 128, 243-249.

Sternad, D., Wei, K., Diedrichsen, J., and Ivry, R.B. (2007). Intermanual interactions during initiation and production of rhythmic and discrete movements in individuals lacking a corpus callosum. Exp. Brain Res. 176, 559-574.

Sun, S.W., Liang, H.F., Trinkaus, K., Cross, A.H., Armstrong, R.C., and Song, S.K. (2006). Noninvasive detection of cupri- zone induced axonal damage and demyelination in the mouse corpus callosum. Magn. Reson. Med. 55, 302-308.

Swinnen, S.P., and Wenderoth, N. (2004). Two hands, one brain: cognitive neuroscience of bimanual skill. Trends Cogn. Sci. 8, $18-25$.

Swinnen, S.P. (2002). Intermanual coordination: from behavioural principles to neural-network interactions. Nat. Rev. Neurosci. 3, 348-359.

Tiffinn, J., and Asher, E.J. (1948). The Purdue pegboard; norms and studies of reliability and validity. J. Appl. Psychol. 32, 234-247.

Tournier, J.D., Mori, S., and Leemans, A. (2011). Diffusion tensor imaging and beyond. Magn. Reson. Med. in press (DOI 10.1002/mrm.22924).

Van Hecke, W., Leemans, A., D'Agostino, E., De Backer, S., Vandervliet, E., Parizel, P.M., and Sijbers, J. (2007). Nonrigid coregistration of diffusion tensor images using a viscous fluid model and mutual information. IEEE Trans. Med. Imaging 26, 1598-1612.

Van Hecke, W., Sijbers, J., D'Agostino, E., Maes, F., De Backer, S., Vandervliet, E., Parizel, P.M., and Leemans, A. (2008). On the construction of an inter-subject diffusion tensor magnetic resonance atlas of the healthy human brain. Neuroimage 43, 69-80.

Van Hecke, W., Sijbers, J., De Backer, S., Poot, D., Parizel, P.M., and Leemans, A. (2009). On the construction of a ground truth framework for evaluating voxel-based diffusion tensor MRI analysis methods. Neuroimage 46, 692-707.

Verhoeven, J.S., Sage, C.A., Leemans, A., Van Hecke, W., Callaert, D., Peeters, R., De Cock, P., Lagae, L., and Sunaert, S. (2010). Construction of a stereotaxic DTI atlas with full diffusion tensor information for studying white matter maturation from childhood to adolescence using tractography-based segmentations. Hum. Brain Mapp. 31, 470-486.

Vos, S.B., Jones, D.K., Viergever, M.A., and Leemans, A. (2011). Partial volume effect as a hidden covariate in DTI analyses. Neuroimage 55, 1566-1576.

Wahl, M., Lauterbach-Soon, B., Hattingen, E., Jung, P., Singer, O., Volz, S., Klein, J.C., Steinmetz, H., and Ziemann, U. (2007). Human motor corpus callosum: topography, somatotopy, and link between microstructure and function. J. Neurosci. 27, 12132-12138.

Wallen, M.A., Mackay, S., Duff, S.M., McCartney, L.C., and O'Flaherty, S.J. (2001). Upper-limb function in Australian children with traumatic brain injury: A controlled, prospective study. Arch. Phys. Med. Rehabil. 82, 642-649.

Wang, J.Y., Bakhadirov, K., Devous, M.D. Sr., Abdi, H., McColl, R., Moore, C., Marquez de la Plata, C.D., Ding, K., Whittemore, A., Babcock, E., Rickbeil, T., Dobervich, J., Kroll, D., Dao, B., Mohindra, N., Madden, C.J., and Diaz-Arrastia, R. (2008). Diffusion tensor tractography of traumatic diffuse axonal injury. Arch. Neurol. 65, 619-626.

Wenderoth, N., and Weigelt, M. (2009). Visual cues influence motor coordination: behavioral results and potential neural mechanisms mediating perception-action coupling and response selection. Prog. Brain Res. 174, 179-188.

Wenderoth, N., Debaere, F., Sunaert, S., van Hecke, P., and Swinnen, S.P. (2004). Parieto-premotor areas mediate directional interference during bimanual movements. Cereb. Cortex 14, 1153-1163.

Wenderoth, N., Debaere, F., Sunaert, S., and Swinnen, S.P. (2005b). Spatial interference during bimanual coordination: differential brain networks associated with control of movement amplitude and direction. Hum. Brain Mapp. 26, 286-300. 
Wenderoth, N., Debaere, F., Sunaert, S., and Swinnen, S.P. (2005a). The role of anterior cingulate cortex and precuneus in the coordination of motor behaviour. Eur. J. Neurosci. 22, 235-246.

Wenderoth, N., Van Dooren, D.M., Vandebroek, A., De Vos, J., Vangheluwe, S., Stinear, C.M., Byblow, W.D., and Swinnen, S.P. (2009). Conceptual binding: integrated visual cues reduce processing costs in bimanual movements. J. Neurophysiol. 102, 302-311.

Wilde, E.A., Chu, Z., Bigler, E.D., Hunter, J.V., Fearing, M.A., Hanten, G., Newsome, M.R., Scheibel, R.S., Li, X., and Levin, H.S. (2006). Diffusion tensor imaging in the corpus callosum in children after moderate to severe traumatic brain injury. J. Neurotrauma 23, 1412-1426.

Witelson, S.F. (1989). Hand and sex differences in the isthmus and genu of the human corpus callosum. A postmortem morphological study. Brain 112, 799-835.

Wozniak, J.R., Krach, L., Ward, E., Mueller, B.A., Muetzel, R., Schnoebelen, S., Kiragu, A., and Lim, K.O. (2007). Neurocog- nitive and neuroimaging correlates of pediatric traumatic brain injury: a diffusion tensor imaging (DTI) study. Arch. Clin. Neuropsychol. 22, 555-568.

Wu, T., Wang, L., Hallett, M., Li, K., and Chan, P. (2010). Neural correlates of bimanual anti-phase and in-phase movements in Parkinson's disease. Brain 133, 2394-2409.

Address correspondence to: Karen Caeyenberghs, M.D.

Laboratory of Motor Control

Research Center for Motor Control and Neuroplasticity Group Biomedical Sciences K.U. Leuven Tervuursevest 101 B-3001 Heverlee, Belgium E-mail: Karen.Caeyenberghs@faber.kuleuven.be 
